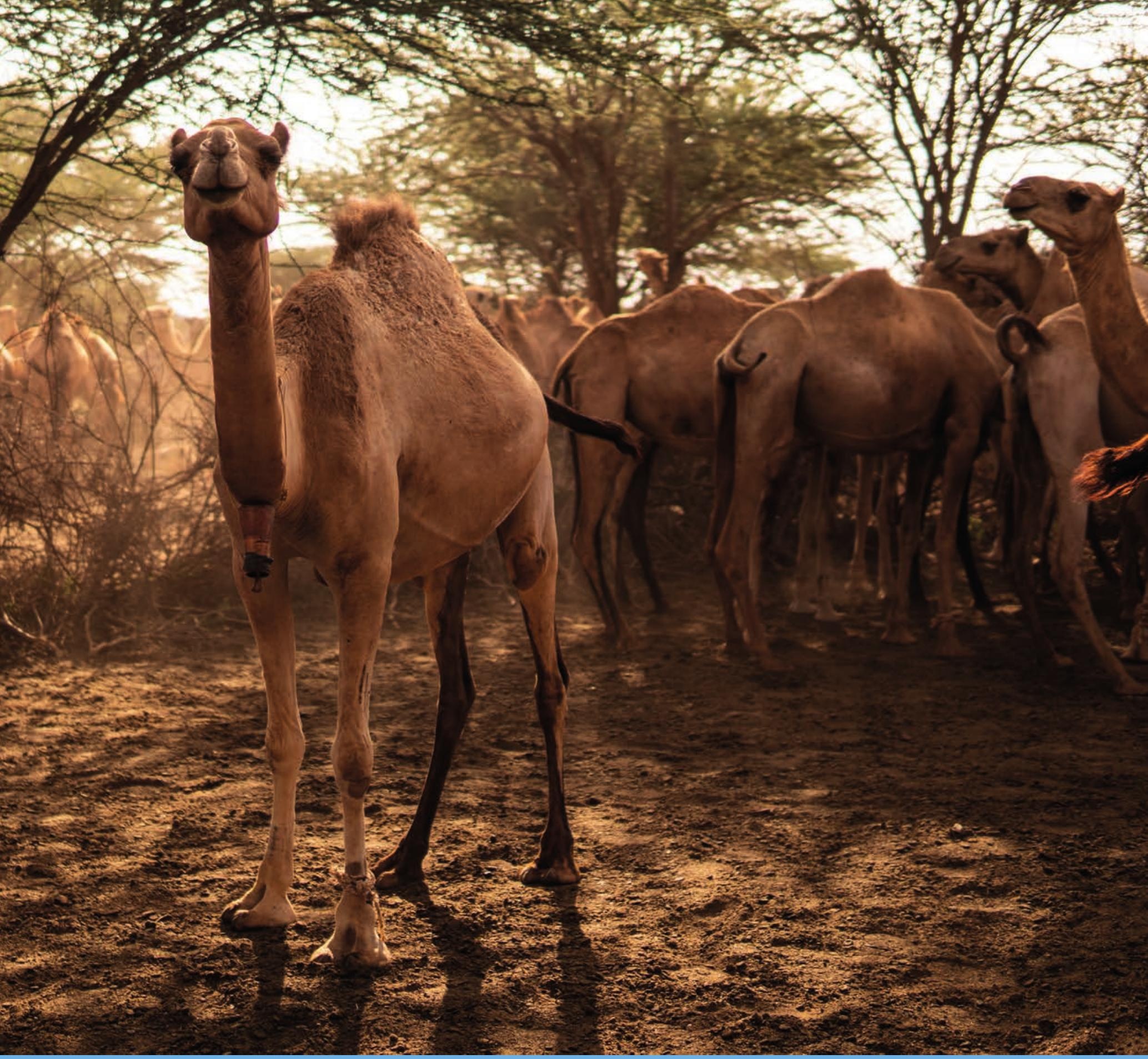

\title{
Building Food System Resilience
} in Protracted Crisis Situations

Food-fodder system resilience assessment and facilitation tool (FoSRA-F-FT)

Version 1.0

Eelke Boerema, Charleen Malkowsky, Gerrit-Jan van Uffelen

WAGENINGEN

UNIVERSITY \& RESEARCH 



\section{Building Food System Resilience in Protracted Crisis Situations}

Food-fodder system resilience assessment and facilitation tool (FoSRA-F-FT)

Version 1.0

Eelke Boerema, Charleen Malkowsky, Gerrit-Jan van Uffelen

Wageningen Centre for Development Innovation

Wageningen, June 2021

Report WCDI-21-154

(working document) 
Eelke Boerema, Charleen Malkowsky, Gerrit-Jan van Uffelen, 2021. Building Food System Resilience in Protracted Crisis Situations; Food-fodder system resilience assessment and facilitation tool (FoSRA-FFT). Wageningen Centre for Development Innovation, Wageningen University \& Research. Report WCDI-21-154. Wageningen.

Building food system resilience in protracted crises is an important goal of Food and Nutrition Security Resilience Programme (REPRO). REPRO adopts a food system - target system interface systems' approach to analyse, understand and build absorptive, adaptive and transformative food system resilience capacities in the face of shocks and stressors, in order to improve food and nutrition outcomes.

Each REPRO country has a specific thematic focus for which a facilitation tool will be developed and published. This working document is a such part of the series of FoSRA publications under FNSREPRO, with s special focus on the food-fodder system interface and its assessment.

This working document is a collaborative effort between the Wageningen Centre for Development Innovation (WCDI) of Wageningen University and Research (WUR) and FAO Somalia under the Food and Nutrition Security Resilience Programme (FNS-REPRO). The proposed methodology and tools will be field tested in Somaliland (Sool and Sanaaq) and validated by the parties mentioned above, based on which a final document will be produced.

This document presents the working document of the food-fodder system resilience assessment and facilitation tool (FoSRA-F-FT). The FoSRA methodology will be employed by Wageningen Centre for Development Innovation (WCDI), in close consultation with FAO, to develop food system resilience pathways in Somaliland as part of the REPRO Programme. There are three interrelated parts of the food system resilience assessment: the FoSRA conceptual framework; the FoSRA field assessment (including an extensive training and tool kit); and learning and knowledge management. The FoSRA-FFT will contribute to developing good practice and policy recommendations in building food system resilience in protracted crisis situations from the perspective of the underpinning fodder system.

Keywords: Somaliland, Food Systems, Resilience, Protracted crisis, Food and Nutrition security, Fodder

This report can be downloaded for free at https://doi.org/10.18174/544801 or at www.wur.eu/cdi (under publications).

(C) 2021 Wageningen Centre for Development Innovation, part of the Stichting Wageningen Research. P.O. Box 88, 6700 AB Wageningen, The Netherlands. T + 31 (0)317 4868 00, E info.cdi@wur.nl, www. wur.eu/cdi.

\section{(cc) BY-NC}

The Wageningen Centre for Development Innovation uses a Creative Commons Attribution 4.0 (Netherlands) licence for its reports.

The user may copy, distribute and transmit the work and create derivative works. Third-party material that has been used in the work and to which intellectual property rights apply may not be used without prior permission of the third party concerned. The user must specify the name as stated by the author or licence holder of the work, but not in such a way as to give the impression that the work of the user or the way in which the work has been used are being endorsed. The user may not use this work for commercial purposes.

The Wageningen Centre for Development Innovation accepts no liability for any damage arising from the use of the results of this research or the application of the recommendations.

Report WCDI-21-154

Photo cover: Shutterstock 


\section{Contents}

BUILDING FOOD-FODDER SYSTEM RESILIENCE IN PROTRACTED CRISIS

$\begin{array}{lc}\text { SITUATIONS } & 5\end{array}$

$\begin{array}{ll}\text { List of abbreviations and acronyms } & 7\end{array}$

$\begin{array}{lr}\text { Concepts and definitions } & 9\end{array}$

$\begin{array}{llr}0 & \text { Introduction } & 11\end{array}$

0.1 Purpose and background $\quad 11$

0.1 .1 Purpose of the document 11

0.1.2 The REPRO programme: building resilient food systems in $\begin{array}{ll}\text { protracted crises } & 11\end{array}$

0.1.3 REPRO's learning agenda in Somaliland: fodder $\quad 12$

0.2 The food-fodder system resilience assessment and facilitation tool 12

$\begin{array}{lll}0.3 & \text { Document Overview } & 15\end{array}$

$\begin{array}{lr}\text { PART I - CONCEPTUAL FRAMEWORK } & 17\end{array}$

$1 \quad$ Component: Understanding food systems and their food and nutrition $\begin{array}{ll}\text { security (FNS) outcomes } & 19\end{array}$

$\begin{array}{lll}1.1 & \text { Food system framework } & 19\end{array}$

1.2 Somaliland: quick scan food systems and FNS outcomes $\quad 21$

1.2.1 How to collect data: desk review and expert consultation $\quad 21$

2 Component: Exploring System Interfaces and FNS 23

2.1 Why Fodder? $\quad 23$

$\begin{array}{lll}2.2 & \text { Fodder System Framework } & 23\end{array}$

2.3 Somaliland: fodder systems, food systems and FNS outcomes 25

2.3.1 Step 1: developing a general understanding of the food-fodder
system interface and FNS outcomes

2.3.2 Step 2: exploring the impact of the risk landscape on fodder and food systems

3

Component: Building food system resilience in protracted crises: applying principles \& practices

3.1 Protracted crisis situations: characteristics, limitations, and constraints

3.2 Principles and practices for strengthening resilience for FNS in protracted crises

3.3 Draft guiding principles of fodder value chain development 27

3.4 Somaliland building local Fodder System Resilience $\quad 28$

3.4.1 Step 1: Define Fodder system resilience as instrumental capacity $\quad 28$

3.4.2 Step 2: Define Fodder / Food system boundaries: archetypes in $\begin{array}{ll}\text { protracted crises } & 28\end{array}$

PART II - FOOD-FODDER SYSTEM RESILIENCE FIELD ASSESSMENT systems and their behaviour 
4.2 Set target system boundaries: archetypes in protracted crises

4.3 Document major shocks \& stressors impacting specific food and fodder systems

4.4 Identify resilience capacities and dynamics in fodder systems 34

4.5 Analysing Food Systems via the Fodder System $\quad 35$ 4.5.1 Exploring the FoSRA Tools

5.1 Identify leverage points

$\begin{array}{lll}5.2 & \text { Define spheres of influence } & 36\end{array}$

$\begin{array}{ll}\text { PART III - LEARNING \& KNOWLEDGE MANAGEMENT } & 37\end{array}$

$6 \quad$ Component: Validate Specific Resilience Pathways $\quad 39$

6.1 Various Potential Validation Approaches 39

6.1.1 Criteria for resilience in food systems 39

6.1.2 Criteria for reduced vulnerability in food systems $\quad 40$

6.1.3 Food systems' contribution to social cohesion, peace, and stability 40 


\section{BUILDING FOOD-FODDER SYSTEM RESILIENCE IN PROTRACTED CRISIS SITUATIONS}




\section{List of abbreviations and acronyms}

FAO

FGD

FNS

FoSRA

FOSRA-F-FT

FSA

FSR

HLPE

IDP

IPC

NGO

UNISDR

UNSCR

WCDI

WUR
Food and Agriculture Organization of the United Nations

Focus Group Discussion

Food and Nutrition Security

Food System Resilience Assessment

Food System Resilience Assessment Facilitation Tool (Fodder version)

Food System Analysis

Food System Resilience

High Level Panel of Experts on Food Security and Nutrition

Internally Displaced People

Integrated Food Security Phase Classification

Non-Governmental Organization

United Nations Office of Disaster Risk Reduction

United Nations Security Council Resolution

Wageningen Centre for Development Innovation, Wageningen University \& Research

Wageningen University \& Research 


\section{Concepts and definitions}

Working definitions for the main concepts used in this document.

\section{Protracted crisis}

Macrae and Harmer (2004) define protracted crises as 'those environments in which a significant proportion of the population is acutely vulnerable to death, disease, and disruption of their livelihoods over a prolonged period of time'.

\section{Resilience}

The United Nations Office of Disaster Risk Reduction definition of resilience: 'The ability of a system, community or society exposed to hazards to resist, absorb, accommodate to and recover from the effects of a hazard in a timely and efficient manner, including through the preservation and restoration of its essential basic structures and functions' (UNDDR, 2015).

In relation to the Rome Based Agencies' focus on agriculture, food security and nutrition, resilience is essentially about the inherent capacities (abilities) of individuals, groups, communities, and institutions to withstand, cope, recover, adapt, and transform in the face of shocks.

\section{Food systems}

According to van Berkum $(2018)^{1}$ : Food systems comprise all the processes associated with food production and food utilisation: growing, harvesting, packing, processing, transporting, marketing, consuming and disposing of food remains (including fish). All these activities require inputs and result in products and/or services, income and access to food, as well as environmental impacts. A food system operates in and is influenced by social, political, cultural, technological, economic and natural environments (HLPE, 2014; Westhoek et al.,2016; Global Panel 2016; HLPE, 2017).

\section{Sustainable food systems}

A sustainable food system is a food system that delivers food security and nutrition for all in such a way that the economic, social, and environmental bases to generate food security and nutrition for future generations are not compromised $\left(\mathrm{FAO}, 2014^{2}\right)$. This means that:

- it is profitable throughout (economic sustainability)

- it has broad-based benefits for society (social sustainability)

- it has a positive or neutral impact on the natural environment (environmental sustainability).

\section{Food System Resilience}

The concept of food system resilience analyses how system components and their actors (from producer, middleman, traders, consumers etc.), are affected by - and respond to shocks and stressors, accounting for ripple effects across the food system, providing insights into varying existing and required resilience capacities and strategies which enable system actors and components to mitigate, prepare for and recover from negative impacts ensuring desired, (improved) socio-economic, environmental and food and nutrition security outcomes. 


\section{$0 \quad$ Introduction}

\section{$0.1 \quad$ Purpose and background}

\subsubsection{Purpose of the document}

This document presents the zero draft of the food system resilience assessment (FoSRA) and facilitation tool (FoSRA-FT). The FoSRA methodology will be employed by Wageningen Centre for Development Innovation (WCDI), in close consultation with FAO, to develop food system resilience pathways in Somaliland as part of the Food and Nutrition Security Resilience Programme ${ }^{3}$ (FNSREPRO, hereafter: REPRO). The FoSRA-FT is being developed as part of REPRO's output 4: REPRO'S learning agenda and knowledge management ${ }^{4}$.

Building food system resilience in protracted crises is an important goal of REPRO Somaliland, taking a food system approach and exploring food and nutrition security (FNS) outcomes. In doing so REPRO Somaliland ${ }^{5}$ focuses on the food-fodder-system interface. These approaches are used to analyse, understand, and promote absorptive, adaptive, and transformative food system resilience capacities in the face of shocks and stressors in order to improve FNS outcomes.

The FoSRA-FT will contribute to developing good practice and policy recommendations in the domain of building food system resilience in protracted crises areas. This document is a working version that is frequently being updated with new insights and experiences of the FNS-REPRO project - thus, whilst the majority of concepts and tools were tested in practice already, some elements are an improved version of the previously implemented approach and methodology, and still await validation. The goal by the end of the project is to produce a final document containing the learnings on food system resilience in protracted crises (in particular the learnings on the food-fodder system interface of the entire 4-year programme), resulting in the compilation of a final framework.

\subsubsection{The REPRO programme: building resilient food systems in protracted crises}

The Netherlands has played a key role in the unanimously adopted Security Council resolution $2417^{6}$ on conflict induced food insecurity. UNSCR-2417 was triggered due to the rise of hunger for the third year in a row; a rise driven by protracted conflict and adverse climate events, and threatening to erode or even reverse gains made in ending hunger and malnutrition (SOFI, 2018) ${ }^{7}$.

The REPRO programme is an initiative by the Dutch Government to operationalise the United Nations Security Council Resolution 2417. This resolution seeks to address food crises and famine as an act or result of war and calls upon the international community to explore new ways to strengthen food system resilience in times of crises and situations of conflict.

REPRO is a four-year programme (2019-2023) funded by the Dutch Ministry of Foreign Affairs and implemented by FAO under its strategic programme 5; it seeks to increase the resilience of livelihoods to threats and crises that affect agriculture, food, and nutrition. The Wageningen Centre for Development Innovation (WCDI) has been subcontracted to implement REPRO's learning agenda and knowledge management. REPRO target countries are Sudan, South Sudan, and Somaliland. This

3 https://www.wur.nl/en/Research-Results/Research-Institutes/centre-for-development-innovation/show-cdi/FNS-REPRObuilding-food-system-resilience-in-protracted-crises.htm

4 FNS-REPRO 2-pager: http://www.fao.org/3/ca6159en/ca6159en.pdf

5 FNS-REPRO Somaliland 2-pager: https://drive.google.com/file/d/16VRKnIL3MgW9MpbDq]WHEId3GM9E12D/view?

6 https://www.un.org/press/en/2018/sc13354.doc.htm

7 The State of Food Security and Nutrition in the World. http://www. fao.org/3/I9553EN/i9553en.pdf 
document focusses on Somaliland only, examining the specific topic of how food and nutrition outcomes can be linked to livestock fodder systems.

\subsubsection{REPRO's learning agenda in Somaliland: fodder}

In Somaliland, the REPRO programme focuses on the role of fodder in building more resilient food systems. Thus, learning is focussed heavily on the food-fodder system interface. Learning and knowledge management are integrated in both REPRO's design to inform adaptive programme management as well as to promote improved policy and practice; it aims to engage at different levels from field-based projects to the Global Network Against Food Crisis ${ }^{8}$.

The learning agenda in Somaliland focusses largely on the exploration of the four future scenarios or pathways ${ }^{9}$, and the development of fodder systems underpinning them for the future of pastoralists / livestock keepers.

FNS-REPRO proposed activities centred on the fodder value chain in Somaliland aim to increase the resilience of communities and their food security status by developing a learning agenda along the following topics:

- Increasing fodder and feed productivity and reducing production costs, through capacity building, aggregation, increasing storage capacity and processing capacity, and achieving economies of scale.

- Restoration of degraded rangelands and actions against desertification, such as Prosopis management and community tree planting.

- Strengthening the capacity of agro-pastoral and pastoral producer organizations to effectively participate in the feed/fodder value chain.

- Promoting good agriculture practices to maximize crop yields and improve the nutrition quality of crop residues while diversifying food available for people.

\subsection{The food-fodder system resilience assessment and facilitation tool}

As Figure 1 below presents, there are three interrelated parts of the food system resilience assessment and facilitation tool:

- I. The FoSRA conceptual framework (green, left side)

- II. The FoSRA field assessment including the FoSRA toolbox (blue, right side); and

- III. Learning and knowledge management (red, bottom part)

I. The FoSRA conceptual framework is made up of three components

- understanding food systems and their FNS outcomes (component 1)

- exploring the food-fodder system interface (Somaliland) and its contribution to FNS outcomes; (component 2) and

- applying principles and practices to building food system resilience in protracted crises (component 3)

II. The FoSRA field assessment consists of two components:

- applying interactive tools to understand Somaliland's food-fodder systems and their behaviour (component 4); with support of a toolbox provided in annex 1 (the toolbox consists of two parts:

1) stakeholders to co-create an understanding of food systems)

- developing food system resilience pathways with a focus on fodder chains in support of food systems' resilience and improved FNS outcomes (component 5) and

8 http://www.fightfoodcrises. net/

9 These 4 scenarios or pathways developed along the four livelihood strategies determined by access to resources (such as water, rangeland, browse) and markets (Catley, et al., 2013) 
III. Learning and knowledge management section consists of:

- validating pathways through questioning (component 6 )

- documenting good practises developing policy recommendations and strengthening concepts (component 7).

Figure 1 provides an overview of the FoSRA-FT. The structure of the document is in line with the main components of the FoSRA framework, meaning that component 1 is introduced in chapter 1 , component 2 in chapter 2 , and so forth. 


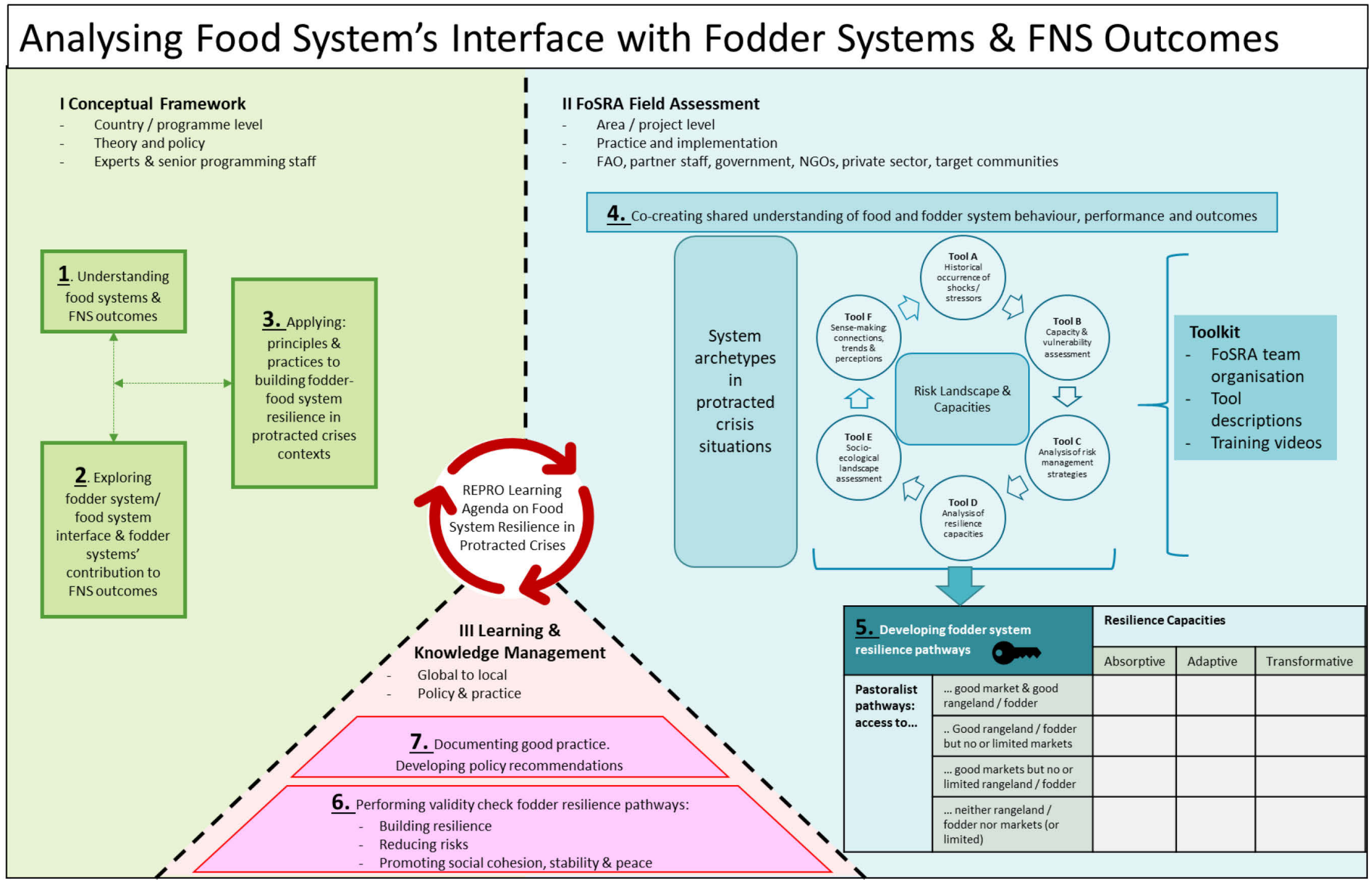

Figure 1 Food-fodder system resilience assessment and facilitation tool. 


\subsection{Document Overview}

As the framework in Figure 1. presents, this document is organised into three main parts:

I. Conceptual Framework, II. The FoSRA Field Assessment, and III. Learning and Knowledge Management.

This first part, the Theoretical Framework, presents the theories, concepts, and principles required in building food system resilience during a protracted crisis. This part is of interest to policy makers, donors, and senior programme staff of implementing agencies involved in food and nutrition security programming. This part of the FoSRA-FT framework aims to: increase understanding of how food systems work and produce/deliver FNS outcomes (component 1); explore the interface between the food system and a critical component, fodder, underpinning the resilience of the food system (component 2), and apply principles to building food system resilience in protracted crisis contexts.

The second area of the framework, the FoSRA Field Assessment, aims to gather information to cocreate a joint understanding of food and fodder system dynamics and behaviours, specifically focussing on shocks, stressors, and resilience capacities (component 4) - this section is also further deepened through the introduction of interactive tools (4.5.1 and appendices). The following section (section 5) explains how, on the basis of these insights, specific pathways can be identified to strengthen resilience capacities of the fodder system that underpins food system resilience (component 5). This part of the report is of key interest to the agency that engages with local actors and stakeholders to implement the FoSRA.

The third part of the report captures learning and knowledge management aiming to validate the findings of the FoSRA, document good practice and develop policy recommendations on food and fodder system theory, concepts and principles. 


\section{PART I - CONCEPTUAL FRAMEWORK}

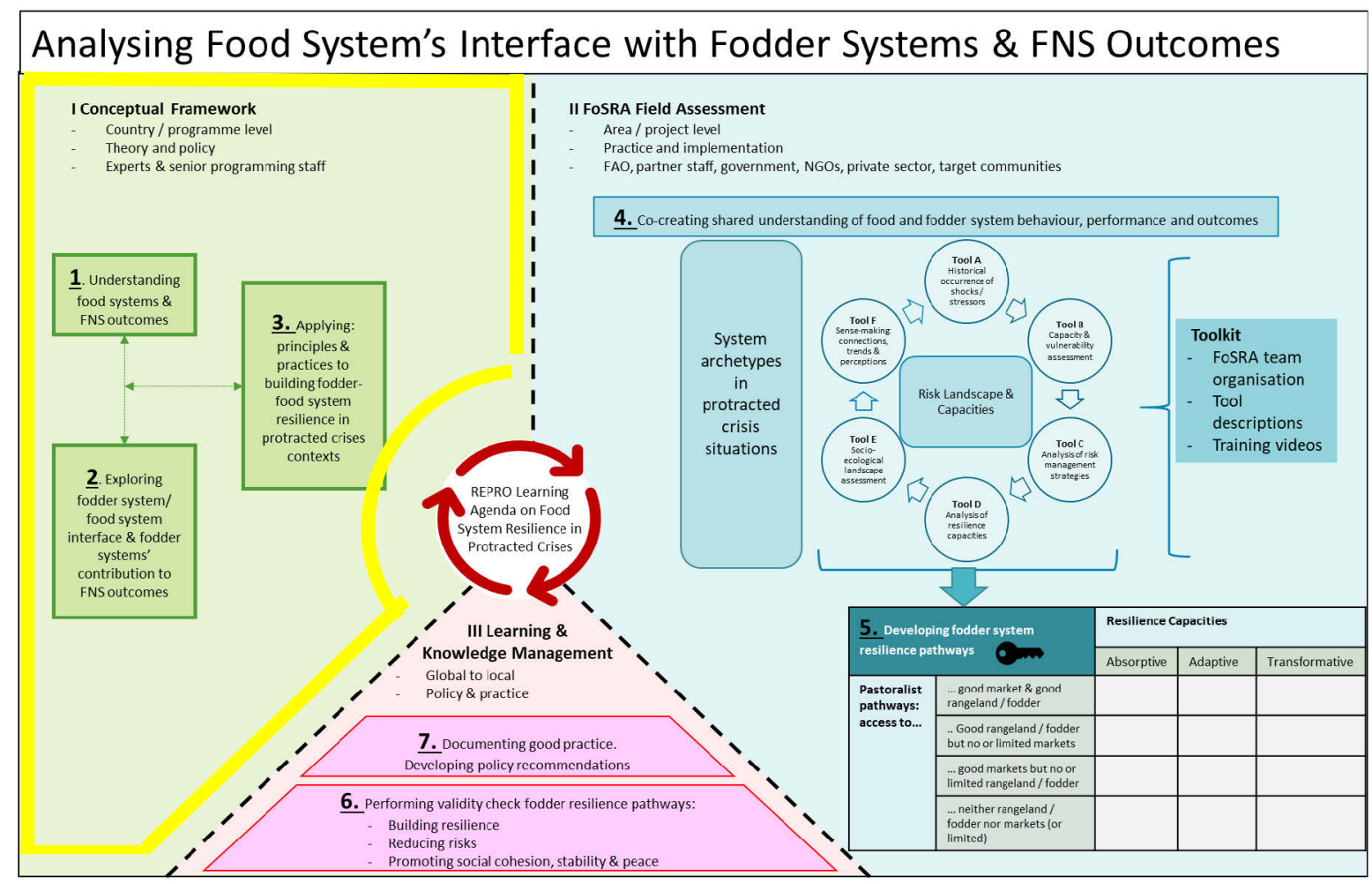

Part I establishes the conceptual framework for the FoSRA assessment. It explains how a food system is analysed, how to make sense of the food-fodder system interface, and how guiding principles are applied. 


\section{Component: Understanding food systems and their food and nutrition security (FNS) outcomes}

Output: gaining a general understanding of food systems and their food and nutrition security (FNS) outcomes. This step will generate an overall understanding of food systems and the resulting FNS outcomes as an overall background to exploring the food-fodder system interface (2. Component).

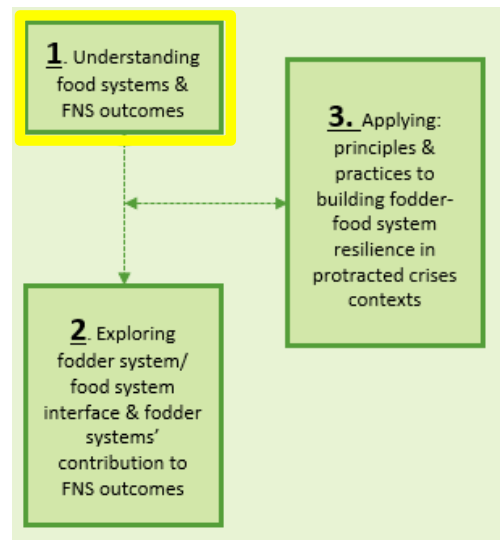

\subsection{Food system framework}

The food system framework developed by van Berkum (2018) is adopted to:

- provide a structured checklist of topics

- draw attention to the potential vulnerabilities of the food system

- identify the most limiting factor(s) to achieving FNS.

Information is collected on food system activities (food supply system and other food system activities and processes, see orange wheel in Figure 2), their socio-economic (blue wheel in Figure 2) and environmental drivers (green wheels in Figure 2), and their impact the final food system outcomes. A stakeholder analysis of the key actors involved in food systems is also part of the analysis.

Data on major shocks and their impact on food systems is included in the analysis as they are important drivers of food system outcomes (outer circle in Figure 2). 


\section{Food systems framework}

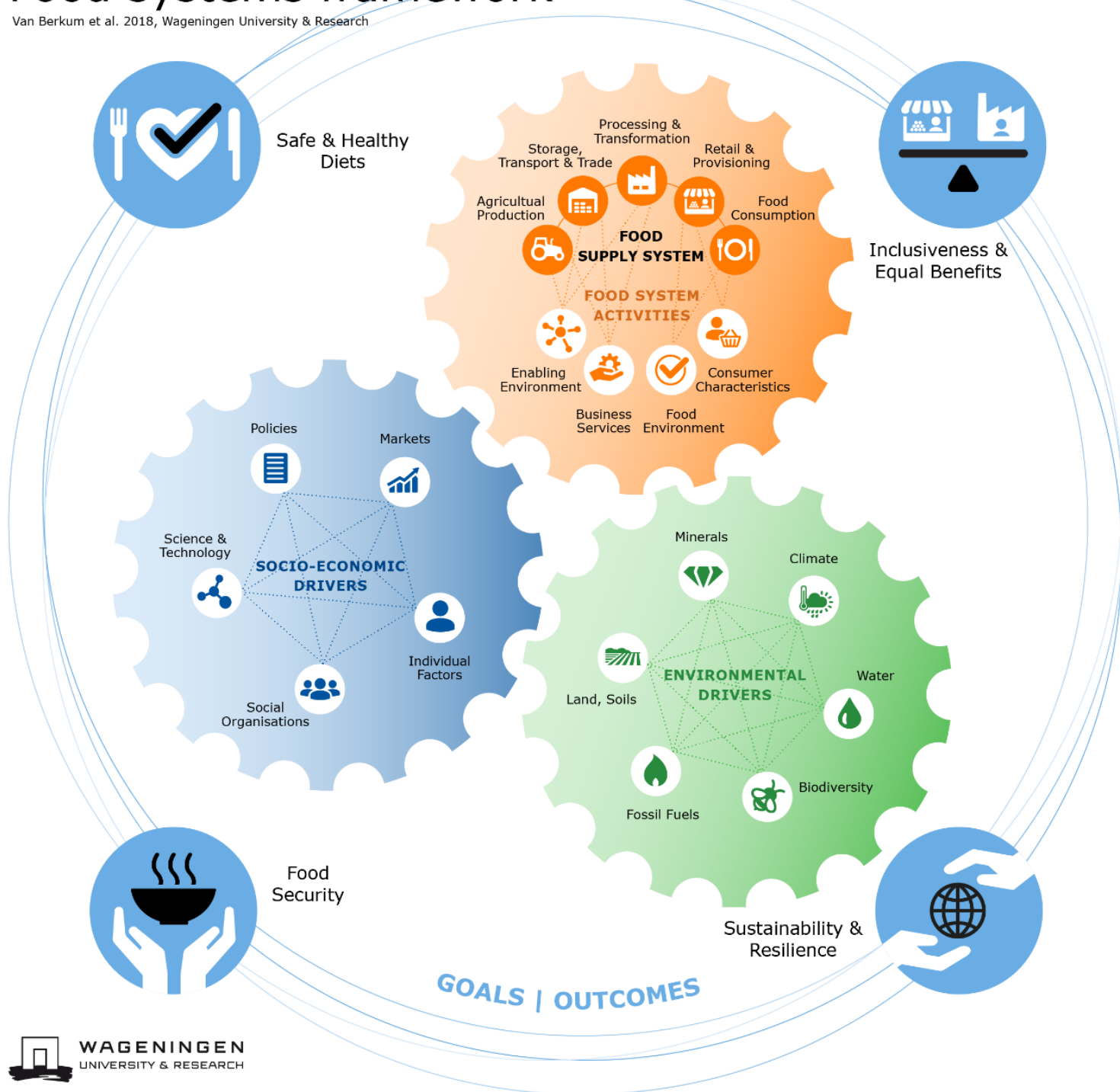

Figure 2 Mapping the food system and its relationship with drivers (Berkum et al, 2018).

Outcomes cover: Safe and Healthy Diets, Inclusiveness \& Equal Benefit, Sustainability \& Resilience and Food Security. The main focus of FNS-REPRO and respective assessments is the Food Security aspect (and healthy diets in the nutrition sense), however, the other dimensions are taken into account where feasible. The FNS outcomes are well documented, and data can be accessed through the Global Report on Food Crises $2020^{10}$, the Integrated Food Insecurity Phase Classification ${ }^{11}$, the Global Report on IPC levels/numbers and FNS outcomes/and forecasts ${ }^{12}$, and other assessments (for example, Crop and Food Security Assessment Mission reports).

There are also other frameworks on food systems, most notable of which is the HLPE food system framework ${ }^{13}$, which following working versions of the document may build upon.

\footnotetext{
https://www.fsinplatform.org/global-report-food-crises-2020

http://www.ipcinfo.org/

2 https://fews.net/IPC

13 http://www.fao.org/fileadmin/user_upload/hlpe/hlpe_documents/HLPE_Reports/HLPE-Report-12_EN.pdf
} 


\subsection{Somaliland: quick scan food systems and FNS outcomes}

The quick scan is being conducted on the specific country level to gather information on the national or regional food system and its outcomes. In this REPRO case, it is the Somaliland food system.

\subsubsection{How to collect data: desk review and expert consultation}

Information and data can be collected via a desk review and consultations of available national and local data, using any or a combination of the following ways:

- a literature review

- documentation available through relevant institutions and for a, such as IPC and food security clusters

- use of expert knowledge (thematic/geography)

\section{Data Sources}

Some general sources of relevant information are presented below.

> FNS Somaliland country profile and descriptions:

https://www.fsinplatform.org/global-report-food-crises-2020.

$>$ The State of Food Security and Nutrition in the World:

http://www.fao.org/publications/sofi/2020/en/

$>$ IPC country updates:

http://www.ipcinfo.org/ipcinfo-website/where-what/east-and-central-africa/somalia/en/

$>$ Agro-ecology, markets, livelihoods:

https://fews. net/east-africa/somalia

> Food Systems Dashboard for general information on country food systems

https://foodsystemsdashboard.org/countrydashboard 


\section{Somalia}

\section{ACUTE FOOD INSECURITY \\ 2019}

Total population of country $12.3 \mathrm{M}$

\section{5\% Rural}

45\% Urban

Population analysed $12.3 \mathrm{M}$ (100\% of total population, induding IDPs, but Not refugees)

\section{i⿱宀 $2.1 \mathrm{M}$

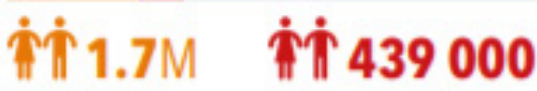 \\ IPC Phase 3 Crisis IPC Phase 4 Emergency}

2018-19 Change

Despite poor rains, floods and insecurity the number of people in Crisis or worse (IPC Phase 3 or above) decreased since 2018 when households were still recovering from the 2016/17 drought.

\section{Forecast}

Improving food security conditions are forecast due to the favourable impact of rains on crop and livestock production, although desert locust infestations are likely to have a negative impact on crop production.

\section{NUTRITION INDICATORS}

\section{Host population}

8. $1.1 \mathrm{M}$ children under 5 years are acutely malnourished, of whom 178000 are affected by SAM.

触 $25.3 \%$ of children under 5 years are stunted.

\section{Refugee population}

$18 \%$ of children under 5 years are acutely malnourished, of whom $3.5 \%$ are affected by SAM.

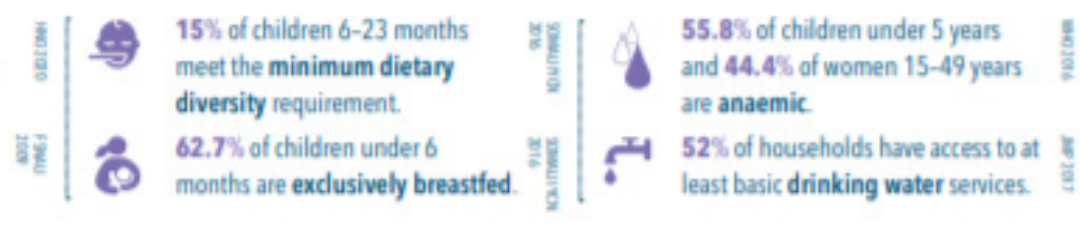

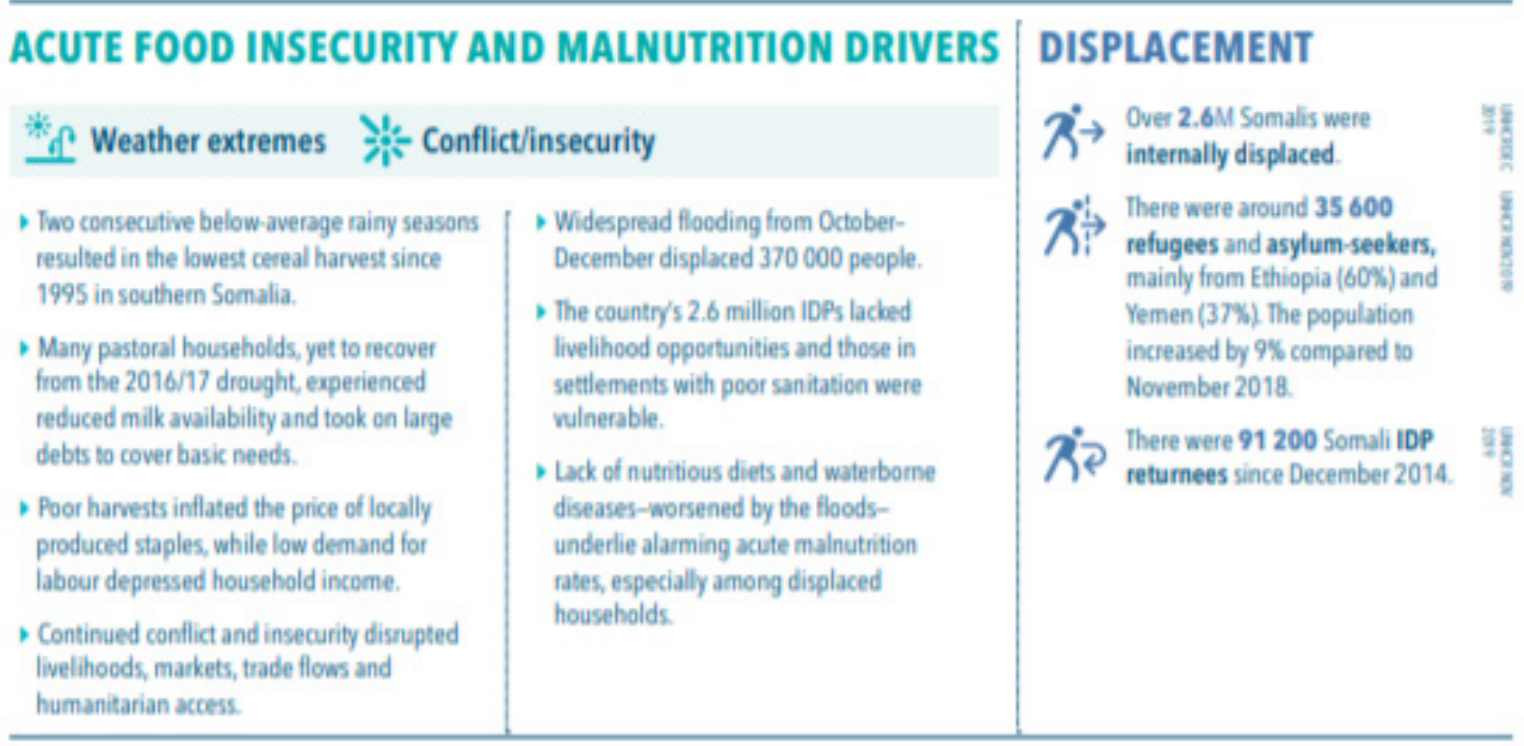

Figure 3 Somalia Country Profile Acute Food Insecurity (FAO, 2020). 


\section{Component: Exploring System Interfaces and FNS}

Output: Understanding the critical role of specific (target) systems such as the fodder system in underpinning food systems and the contribution of food systems to FNS outcomes.

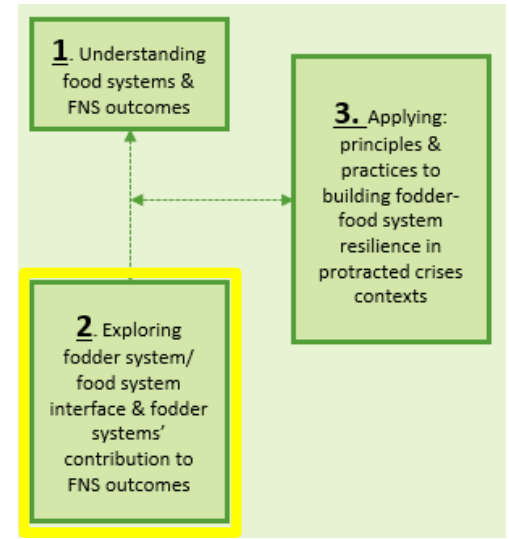

\subsection{Why Fodder?}

During an early FNS-REPRO scoping mission, fodder was identified as a promising system to focus efforts on since it has been neglected in large-scale programming so far and shows the potential to be a leverage point in food system strengthening due to Somaliland's dominant livestock economy.

\subsection{Fodder System Framework}

Subedi and Vernooy (2019) ${ }^{14}$ developed a framework of resilient seed systems for healthy food systems by adapting Van Berkum's $(2018)^{15}$ food system model. This model was further adapted to fit fodder systems as well, showing how fodder actors and activities interact with environmental and socio-economic drivers and how this all links to food system outcomes.

The model therefore allows the exploration of fodder, its outcomes, and interactions with food systems and food system outcomes. By doing so, critical challenges and gaps can be identified to strengthen fodder systems and their contribution to food system outcomes.

The model does not explicitly mention the impact of shocks and stressors on fodder systems and their interaction with fodder system/food system outcomes. It is, however, clear that shocks and stressors shape socio-economic (as well as socio-politico-economic) and environmental drivers that, themselves, impact fodder actors and activities.

The framework below illustrates and conceptualises the interface of fodder and food systems (Figure 4).

\footnotetext{
14 Based on 'Healthy food systems require resilient seed systems': https://cgspace.cgiar.org/handle/10568/105871

15 The food systems approach: sustainable solutions for a sufficient supply of healthy food: 


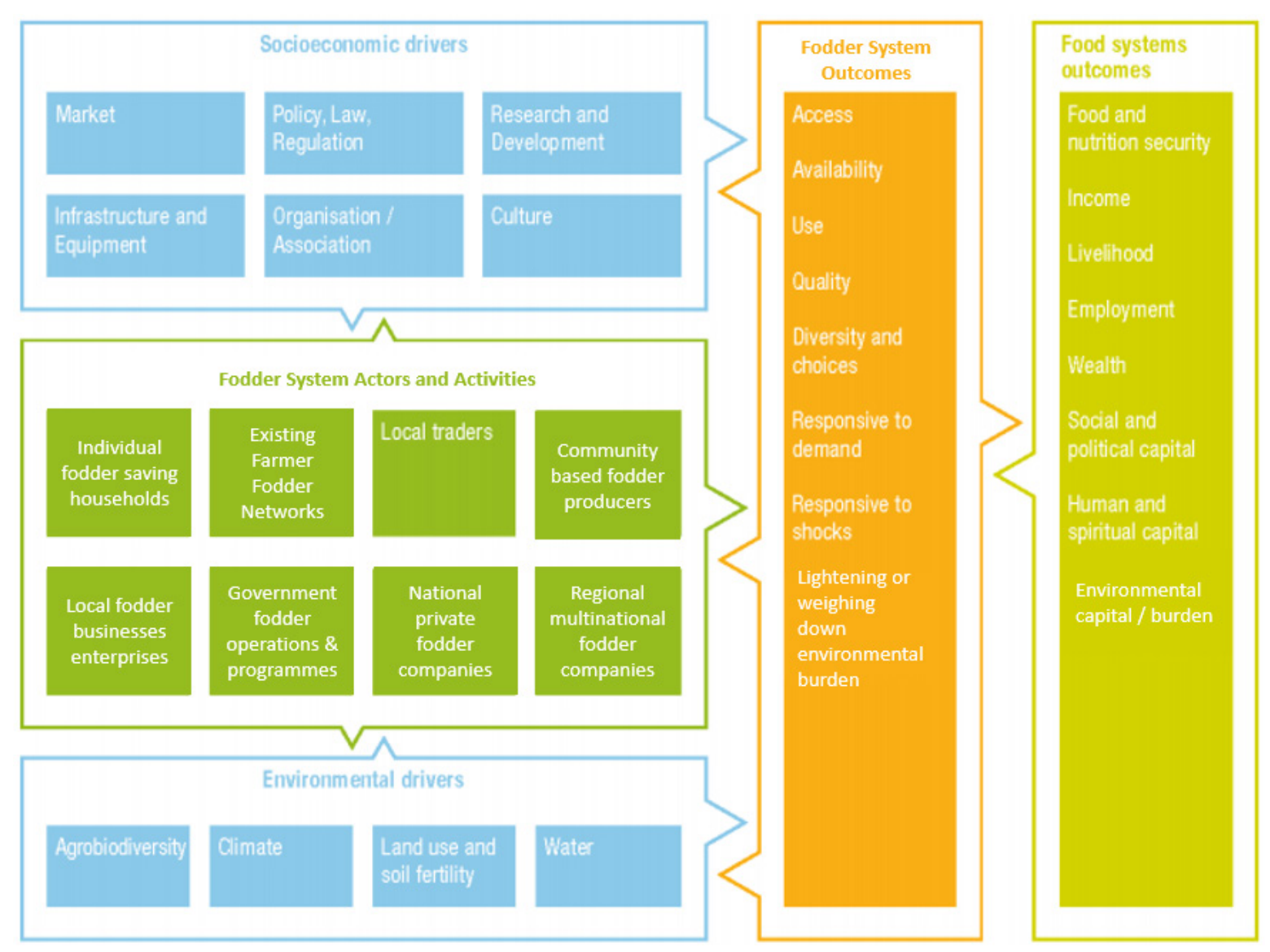

Figure 4 Framework for resilient fodder systems for healthy food systems (adapted from Subedi and Vernooy, 2019).

How fodder systems underpin a healthy food system:

- The establishment / strengthening of a fodder value chain creates jobs for population groups with limited market and rangeland access (Catley, et al., 2013), hence providing an income source to increase purchasing power for food items in population groups that are not as directly involved in the livestock business. This new income is stabilised through the link to the predominant livestock economy which is likely to persist in the near future.

- A resilient fodder system depends on innovative business models and value chains, as well as the empowerment of farmers and local implementation of international and national policies.

- Fodder availability impacts food security by feeding livestock in times of shocks and stressors or if the natural pasture lands cannot carry the burden of grazing. For example, in Somaliland, according to assessments made with households affected by the 2016 drought, $88 \%$ of the respondents who reported livestock as their main source of income also reported that the body condition of their animals was "thin"; of those $88 \%$ a further $82 \%$ reported the body condition of their animals as "very thin" (Ministry of National Planning and Development, 2019). The most affected regions where body condition of animals was reported as "very thin" were Sanaag (36\% of households), Toghdeer $(25 \%)$, and Sool (20\%). Of the households that reported the body condition of their animals as "very thin", 96\% reported that they had no stock of fodder (Waithanji, 2020). Hence, interventions in the fodder chain can lead to a better availability and accessibility of fodder sources to improve livestock conditions. This allows for income generation through exporting healthy livestock or to FNS outcomes through direct consumption of animal products.

- $85 \%$ of Somaliland's export is livestock revenues, indicating the potential high level of impact that fodder systems can have on overall food systems in such a livestock-export-oriented economy (Waithanji, 2020). 


\subsection{Somaliland: fodder systems, food systems and FNS outcomes}

\subsubsection{Step 1: developing a general understanding of the food-fodder system interface and FNS outcomes}

This step develops an understanding of the causal interrelationship (key processes and feedback loops) between food and fodder systems and how this affects FNS outcomes.

Information and data can be collected via a desk review of available national and local data complemented or enriched by consultations. Data can be collected using any or a combination of the following ways:

- literature research

- documentation available through relevant institutions and forums such as FAO, specialised agencies, and professional bodies for example Food Security Clusters

- consultations with knowledge experts (thematic/geography)

- national level consultations with key stakeholders in food-fodder systems.

A potential tool to be utilised in consultation workshops is the causal diagram, which can be used to depict which factors influence what, and whether a change in one factor causes a similar or opposite change in another factor. Attention is given to feedback loops and whether these result in the reinforcement, balancing, or erosion of food and fodder system dynamics and their contribution to FNS outcomes.

\subsubsection{Step 2: exploring the impact of the risk landscape on fodder and food systems}

This step identifies the main hazards (shocks and stressors), the exposure to hazards and the likelihood of suffering harm (susceptibility).

Exploring the risk landscape includes objective measures on shocks/stressors (i.e., intensity, scope, and frequency) and subjective measures (i.e., the perceived effect of shocks/and stressors on fodder systems and FNS outcomes).

How to collect data: desk review and expert consultation

Information and data can be collected via a desk review of available national and local data. Data can be collected using any of the following ways:

- literature research

- documentation available through relevant institutions and fora such as FAO, specialised agencies, and professional bodies for example Food Security Clusters

- use of expert knowledge (thematic/geography) 


\section{Component: Building food system resilience in protracted crises: applying principles $\&$ practices}

Output: understanding the challenges and applying principles and practices to building food system resilience through strengthening the underpinning fodder system for improved FNS outcomes in protracted crises.

Building fodder system resilience in protracted crises to address food system resilience requires:

- understanding the characteristics, limitations, and constraints of operating in protracted crisis contexts

- adopting approaches to building resilience for food and nutrition security

- applying the principles for promoting integrated fodder system

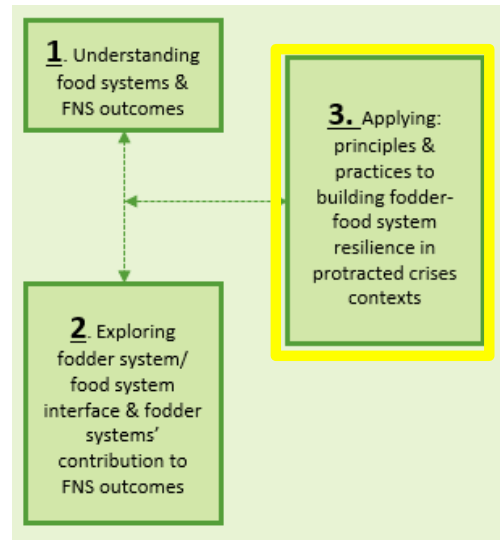
development.

\subsection{Protracted crisis situations: characteristics, limitations, and constraints}

In identifying resilience goals for a specific target system such as fodder, it is important to consider the constraints on addressing FNS in protracted crises, and the implications of these.

Protracted crises are heterogeneous but are nevertheless defined by several characteristics (Maxwell, 2011) ${ }^{16}$ :

- Protracted crises are defined by both time duration and magnitude. Many have lasted for 30 years or more and are characterized by extreme levels of food insecurity.

- Few protracted crises are traceable to a single, acute shock. Conflict is often a cause, but climatic, environmental, or economic factors may also be causes. Unsustainable livelihoods are both a consequence and cause of protracted crises.

- Intervention mechanisms are often weak. Development donors are often unwilling to make significant investments in protracted crisis contexts, and private-sector engagement in protracted crises is often lacking or dominated by informal or illegal economic activities that extract wealth but do little to reinvest in sustainable improvements. Thus, market-led and technology-driven development is extremely difficult to sustain in protracted crises.

- Protracted crises remain on the humanitarian agenda in part because of poor food security or nutritional outcomes, and in part because humanitarian agencies are often the only available vehicle for intervention under the prevailing architecture of international assistance.

- Protracted crises often occur in contexts in which states are incapable or unwilling to provide basic services or infrastructure or are downright predatory toward the population. In short, protracted crises, and the populations caught in them, fall between standard categories of intervention and are often forgotten.

There are conceptual limitations and institutional constraints to working in protracted crises, limited growth potential from private sector investment, various constraints to public-sector or international programmatic interventions, and no consensus on operating principles or priorities. In general, three types of limitations exist (Maxwell, 2011).

16 Maxwell, D., L. Russo and Luca Alinovi, 2011. Constraints to addressing food insecurity in protracted crises. https://www.ncbi.nlm.nih.gov/pmc/articles/PMC3411957/ 
- Conceptual limitations: external interventions are organized on the normative assumption that humanitarian assistance is to save lives in disaster/crises context and that with recovery the trajectory returns to improvement and development.

- Institutional constraints: a major institutional factor constraining livelihood change in protracted crises is the bifurcation of donor funding (between relief and development).

- Programming constraints: several programming constraints limit external interventions. One is the limitation(s) of the dominant programmatic framework; another includes practical elements of programme management; a third is normative (humanitarianism as a principled approach addresses individual needs and development, with a focus on state/government building.

\subsection{Principles and practices for strengthening resilience for FNS in protracted crises}

The Rome-based Agencies' Conceptual Framework for Strengthening Resilience for Food Security and Nutrition in Protracted Crises Contexts ${ }^{17}$ presents key principles and practices to support the resilience of individuals, households, and communities. These are:

- Local and national ownership and leadership: people, communities and governments must lead resilience-building for improved food security and nutrition.

- A multi-stakeholder approach: assisting vulnerable people to build their resilience is beyond the capacity of any single institution.

- Combining humanitarian relief and development: planning frameworks should combine immediate relief requirements with long-term development objectives.

- Focus on the most vulnerable people: ensuring protection of the most vulnerable people is crucial for sustaining development efforts.

- Mainstreaming risk-sensitive approaches: effective risk management requires an explicit focus on the decision making of national governments, as well as enhanced monitoring and analysis.

- Aiming for sustained impact: interventions must be evidence-based and focussed on results.

\subsection{Draft guiding principles of fodder value chain development}

FNS-REPRO activities are also designed to help communities make best sustainable use of local resources and manage challenges in innovative ways. Overarching principles of the work under the fodder component are:

- Develop participatory approaches that especially include women and youths in various links of the value chain.

- Promote feed and fodder production methods that are climate-, environment- and resource smart, and that can be sustained by poor (agro) pastoral communities beyond the life of the project, including in seasons of poor rainfall.

- Stimulate the formation of Public-Private-Producer partnerships to address challenges, gaps, and opportunities in the feed/fodder value chain ${ }^{18}$.

As part of the REPRO programme's learning agenda, these principles are tested, validated and adapted. Hence, they should rather be seen as a draft version at this stage.

17 https://docs.wfp.org/api/documents/WFP-0000062320/download/

18 FNS-REPRO proposal, p. 29 


\subsection{Somaliland building local Fodder System Resilience}

\subsubsection{Step 1: Define Fodder system resilience as instrumental capacity}

Gain/build key actors'/stakeholders' understanding of food / fodder system resilience as a functional capacity, through the following key guiding questions for designing resilience interventions to build resilience:

- Resilience of what?

- Resilience to what?

- Resilience for whom?

- Resilience 'through what'?

This will provide the basic rationale for guiding the field-based fodder / food system resilience assessment and should clarify for local actors and stakeholders in the FoSRA the 'hows' and 'whys' of the FoSRA as a foundation for building resilient food systems.

In the case of REPRO Somaliland, this would be the resilience of pastoralist systems and respective connected livelihoods ('of what') towards key shocks and stressors such as droughts, deforestation, and conflicts ('to what') for (agro)-pastoralist households in Sool and Sanaag ('for whom') through the development of a partially commoditised \& supportive feed and fodder system ('through what').

However, the answers to those questions are likely to differ, depending on which of the varying actor groups is being asked - local beneficiaries, policy makers, or international experts. It is important to keep this in mind to mitigate any tensions caused by misunderstandings, and to create a dialogue to facilitate communication with one another in a transparent \& productive manner. This also creates an organic starting point for programming decisions.

How to collect data: desk review and expert consultation Information and data can be collected via a desk review of available national and local data and expert consultations. Data can be collected using any, or a combination of, the following ways:

- literature research, including policy docs and initiatives on promoting resilience

- documentation available through relevant institutions and fora such as FAO, specialised agencies, and professional bodies for example food security clusters

- use of expert knowledge (thematic/geography)

Data sources

Some general sources of relevant information are presented below.

- FSIN series on promoting FNS resilience ${ }^{19}$.

\subsubsection{Step 2: Define Fodder / Food system boundaries: archetypes in protracted crises}

In order to make a meaningful contribution to promoting the fodder sector development in protracted crisis situations, REPRO-Somaliland works in areas that show different food/ fodder system archetypes, all of which are typical for protracted crisis contexts.

Archetypes represent different patterns of food / fodder system behaviour, offering unique leverage points for enabling changes that build more resilient fodder systems, thereby also improving FNS outcomes.

In the example of Somaliland, the fodder sector is not yet well developed whilst the livestock sector is predominant across Somaliland and the Sool and Sanaag regions. Nonetheless, several fodder related activities exist:

- Natural regeneration of rangeland pasture within flooded plains, depressions within the rangeland area (marketed at Berbera Port, produced without fertilising or manuring of the pastures to boost forage productivity)

19 https://www. fsinplatform.org/resilience-measurement 
- Reseeding of degraded rangeland areas aiming trigger biological revival and plant re-colonialization

- Cultivated fodder, which mainly refers to maize/ sorghum stovers left from food crop production

Main regional market hubs are Borama and Hargeisa. Overall, marketing of these fodder sources is very limited and there is little to no involvement of key players such as the government within the fodder value chain, meaning that no structured overview or policy framework exists around the fodder chain (Waithanji, 2020).

The fodder system boundaries and current practices can be further explored in the multidisciplinary context analysis of Somaliland ${ }^{20}$.

How to collect data: desk review and expert consultation Information and data can be collected via a desk review of available national and local data and expert consultations. Data can be collected using any of the following ways:

- literature research including policy documents and initiatives on promoting resilience

- documentation available through relevant institutions and fora such as FAO, specialised agencies, and professional bodies, for example food security clusters

- use of expert knowledge (thematic/geographical)

\section{Data sources}

Some general sources of relevant information (to be accessed geographically disaggregated) are presented below:

> FNS Somalia (Somaliland focus) country profile and description: https://www.fsinplatform.org/global-report-food-crises-2020;

$>$ The State of Food Security and Nutrition in the World: http://www.fao.org/publications/sofi/2020/en/

$>$ IPC country updates http://www.ipcinfo.org/ipcinfo-website/where-what/east-and-central-africa/somalia/en/

> Agro-ecology, markets, livelihoods in Somaliland: https://fews, net/east-africa/somalia

$>$ Food Systems Dashboard for general information on country food systems https://foodsystemsdashboard.org/countrydashboard

20 Waithanji Elizabeth, Khalid Saeed, Tetu Kennedy, Haroon Yusuf, Ahmed Nur, Abdirizak Warsame, Erastus Mbugua and Nimco Hersi. 2020. Food and Nutrition Security Resilience Programme (FNSREPRO): Building food system resilience in protracted crises. Report of The Multi-Disciplinary Context and Fodder Value Chain Analysis in Sool And Sanaag (Somaliland). FAO April 2020 - especially chapter 2.6 and 4.7 


\section{PART II - FOOD-FODDER SYSTEM RESILIENCE FIELD ASSESSMENT}

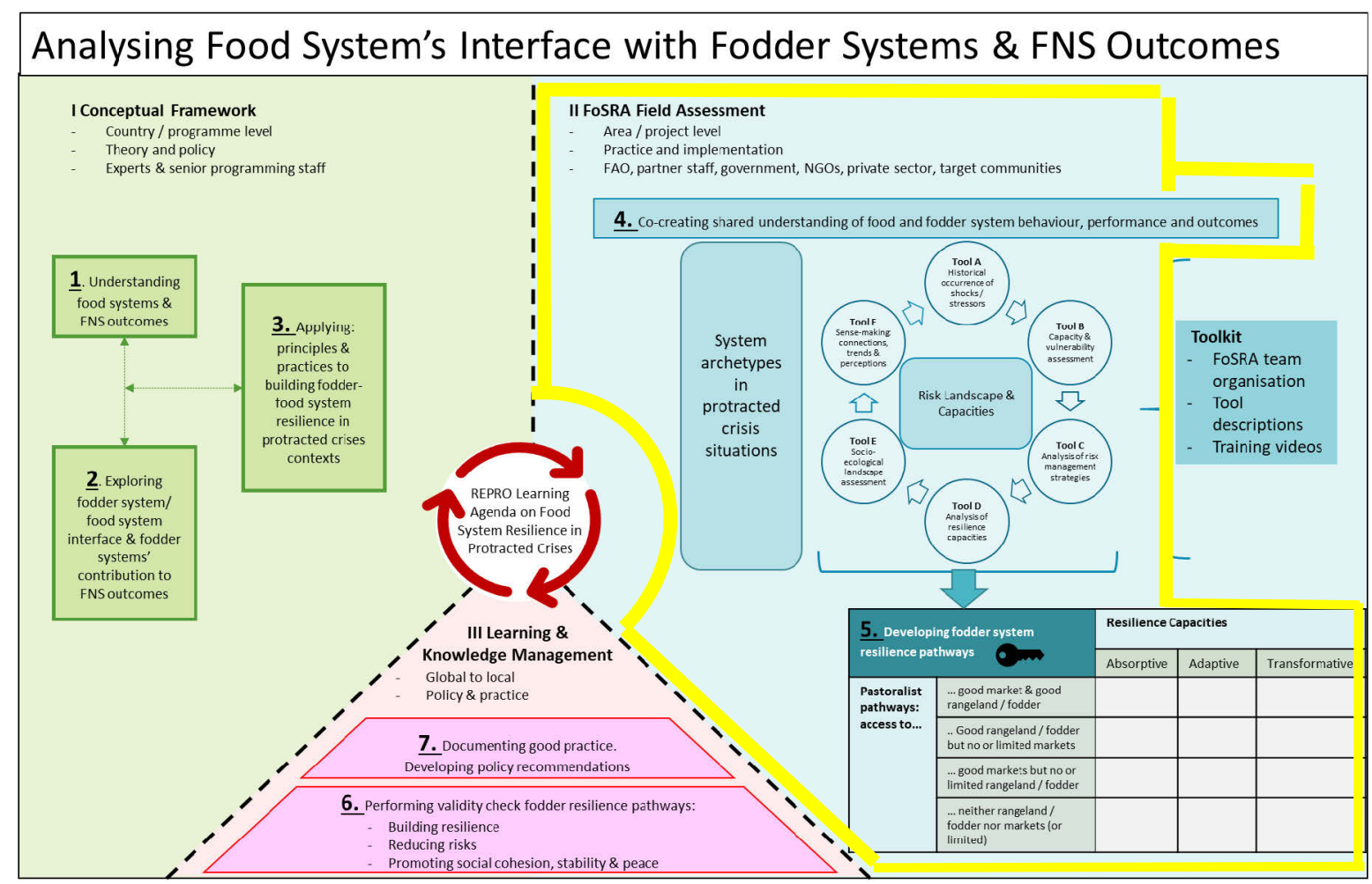

Part II explains the field-based elements of the FoSRA assessment, looking at the definition of foodfodder system boundaries and archetypes, and explaining the relevance of comprehending system behaviour and dynamics in the face of shocks and stressors. The concept of resilience is clarified, and interactive tools to gather this data are integrated and can be explored. Finally, the resilience pathway matrix is introduced which supports the sense-making process of all gathered information from the field. 


\section{Component: Applying interactive tools to understand food-fodder systems and their behaviour}

Output: understanding local food-fodder systems and their behaviour in the face of shocks and stressors.

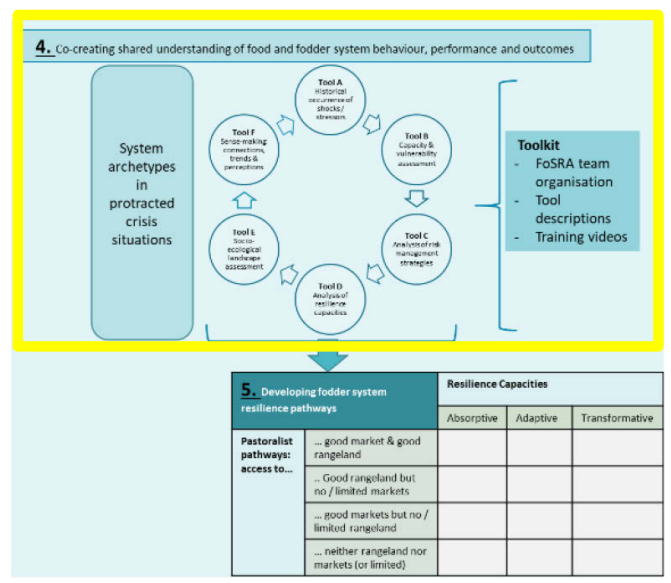

\subsection{Define fodder system resilience as instrumental capacity}

Validate the findings and insights from the national level (see component 3).

\subsection{Set target system boundaries: archetypes in protracted crises}

Develop with local actors and stakeholders the geographical boundaries of the main fodder system archetypes in the locality.

In Somaliland, this includes the areas Sool and Sanaag and their rangelands - and local markets. The current fodder sector is limited; hence, no hotspots of fodder trade can be identified in this area yet.

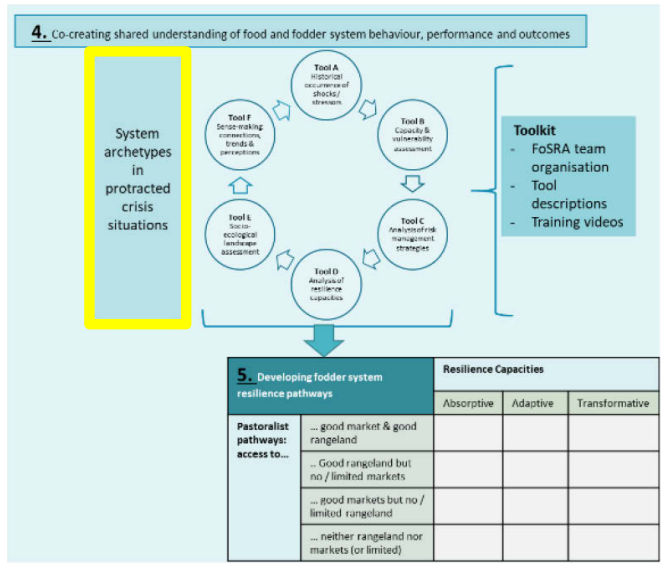

\subsection{Document major shocks \& stressors impacting specific food and fodder systems}

It is important to determine what the major shocks and stressors are in a particular area and how they have, in general, impacted the fodder developments and their interfaces with overall food security.

Particular attention should be given to typical shocks/drivers impacting fodder systems, driving poor FNS outcomes in protracted crisis contexts: conflict/insecurity, economic shocks, and climate shocks.

Major shocks and stressors impacting fodder systems and respective food systems will be identified by local stakeholders and target communities, focusing on their impact on fodder systems and how these systems have changed as a result. 
In focus group discussion (FGD) the most important shocks and stressors over the last 10-15 years should be identified and the impact on fodder as well as food systems should be discussed (this will be further detailed as part of Tool a) historical timeline in the toolkit).

Typical questions to be asked include:

- What are the most important shocks or stressors that impact fodder systems?

- What has changed as a result of that shock/stressor (separate for each shock/stressor on fodder systems, and why?

- What have been the consequences of these changes in dealing with future shocks and stressors?

- What resilience capacities in fodder systems have been instrumental for recovery of these systems for maintaining or improving FNS outcomes?

With regards to conflict and displacement it is important to mention that these often result in changes in land use. For example, displaced communities making use of the land near their new dwellings.

So, an important question may be:

- Have shocks and stressors resulted in different land use patterns?

- Have shocks and stressors impacted the viability of livelihoods or production of fodder in general?

\subsection{Identify resilience capacities and dynamics in fodder systems}

From an analytical perspective, resilience in fodder systems focuses attention on the relationship between them, the impact of shocks and stressors, and the fodder systems' capacity to preserve and improve on FNS outcomes.

Building food system resilience involves strengthening its absorptive, adaptive, and transformative capacities to cope with (and recover from) specific shocks and stressors. Understanding how different types of shocks and stressors affect local fodder systems is fundamental to designing interventions that strengthen their system resilience.

The FoSRA adopts the 3-D resilience framework (Béné, 2012) ${ }^{21}$ to promote food system resilience capacities in the form of context-specific fodder system pathways that strengthen absorptive, adaptive and/or transformational capacities as required for the local context and circumstances.

\begin{tabular}{|c|c|c|}
\hline \multicolumn{3}{|c|}{ Intensity of change / transaction costs } \\
\hline stability & flexibility & change \\
\hline Absorptive coping & Adaptive & Transformative \\
\hline capacity & Capacity & Capacity \\
\hline (persistence) & (incremental adjustment) & (transformational responses) \\
\hline \multicolumn{3}{|c|}{ Resilience } \\
\hline \multicolumn{3}{|c|}{ (Source: Béné et al., 2012, p.21, also see updated version in Béné et al., 2016) } \\
\hline
\end{tabular}

Figure 5 The 3D resilience framework (Béné, 2012).

How to collect data

- use of expert knowledge (thematic/geography); and

- interactive/participatory work with local stakeholders and community groups (KII, FGDs).

21 IDS Working Papier: Resilience, Resilience: New Utopia or New Tyranny? https://onlinelibrary.wiley.com/doi/epdf/10.1111/j.2040-0209.2012.00405.x 


\subsection{Analysing Food Systems via the Fodder System}

To analyse food systems in protracted crises contexts six tools have been developed. These analytical tools will identify and analyse data at household and local community level.

The tools map out and facilitate understanding of local food and fodder systems, how protracted crises affect them, and what actions are being or could be taken to improve resilience. They involve facilitators working with local farmers and/or stakeholders with surveys and workshops to analyse the following:

- Which shocks and stressors occurred in the area in the past 10 years (Tool A)

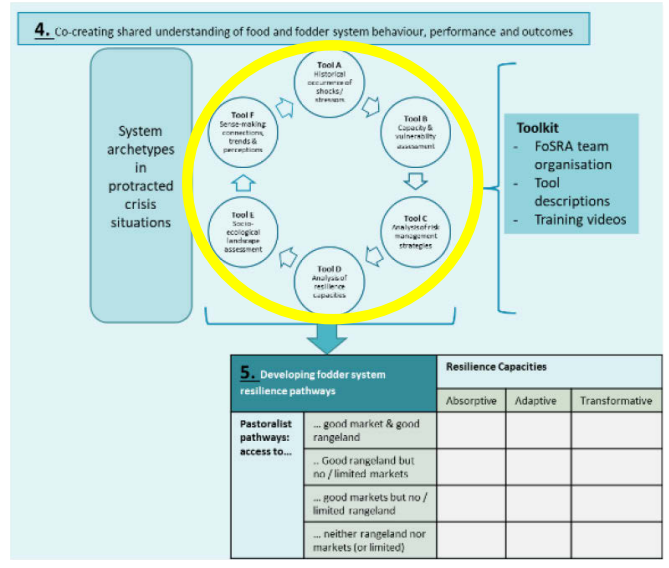

- Which vulnerabilities and capacities are present and required (Tool B)

- Which risk management strategies are prevalent and required (Tool C)

- Which resilience capacities are in place and required (Tool D)

- How communities and the (changing) ecological landscape interact with each other (Tool E); (this tool is still under revision and may be adapted or replaced / supplemented by short courses on landscape governance through a related educational project)

- How all the above logically link together from different perspectives (Tool F)

The tools are organized in six steps that, together, analyse local and regional food systems and give insights for designing appropriate and effective context specific interventions to strengthen food system resilience.

Each tool is connected to the following tools in a sequence, deepening their insights. Results are captured in report summaries, posters, and data sets, produced by the facilitators, that synthesises the information gained from all the workshops and outlines possible actions. This is a strong basis for the next component of the assessment; developing pathways that enable farmers in protracted crises to increase resilience in fodder systems, thus underpinning food system performance and improved FNS outcomes.

\subsubsection{Exploring the FoSRA Tools}

The tools can be explored through the framework extract below. Clicking on the respective tool opens the subsequent Appendix sections where the toolkit is placed.

4. Co-creating shared understanding of food and fodder system behaviour, performance and outcomes

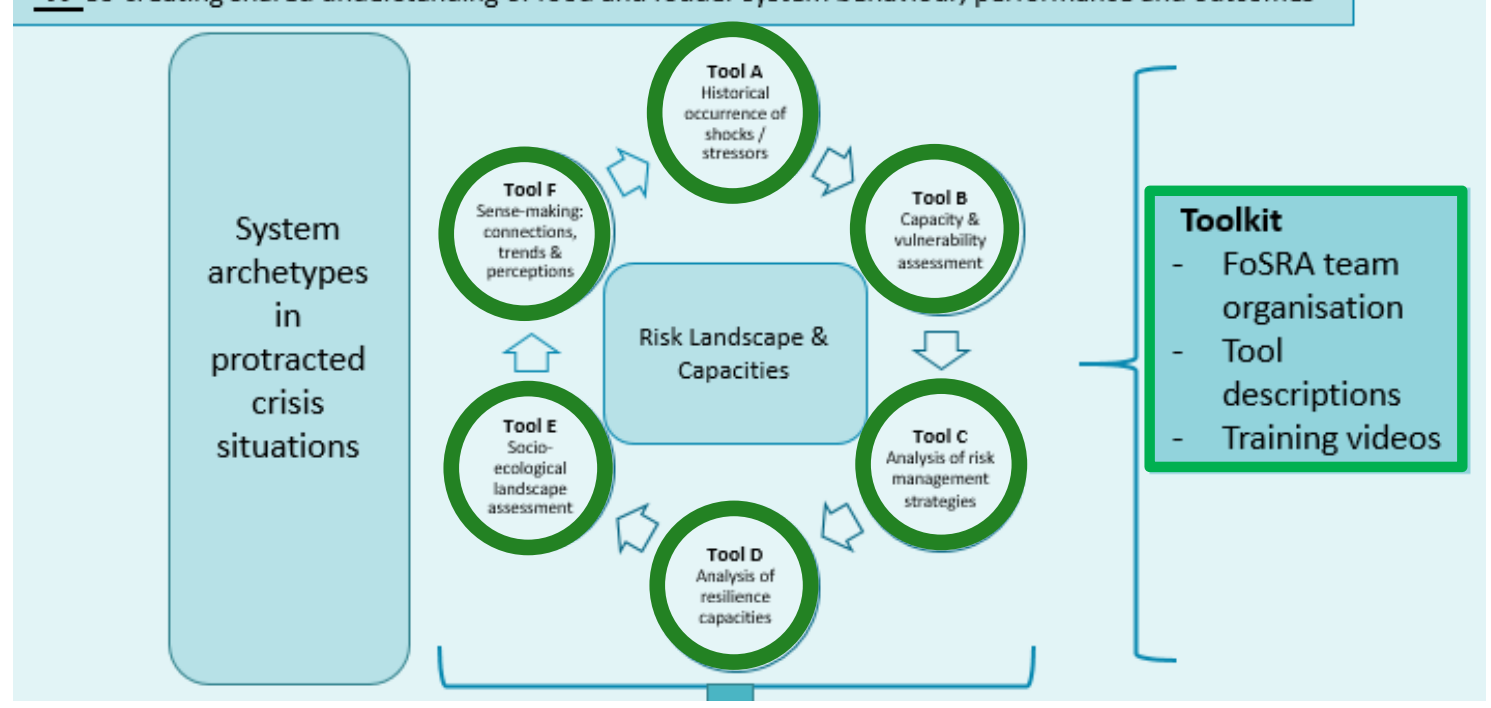




\section{Component: Develop resilience pathways}

Output: development of local fodder system pathways, that address critical gaps in food system resilience and engage relevant actors.

This final step is the matchmaking process whereby policy goals, leverage points, spheres of influence, and policy instruments are brought together to inform foodfodder system resilience pathways that are relevant to local contexts and dynamics.

Fodder system resilience pathways are formulated based on the most promising leverage points that are within, or in reach of, policy goals as well as the spheres of

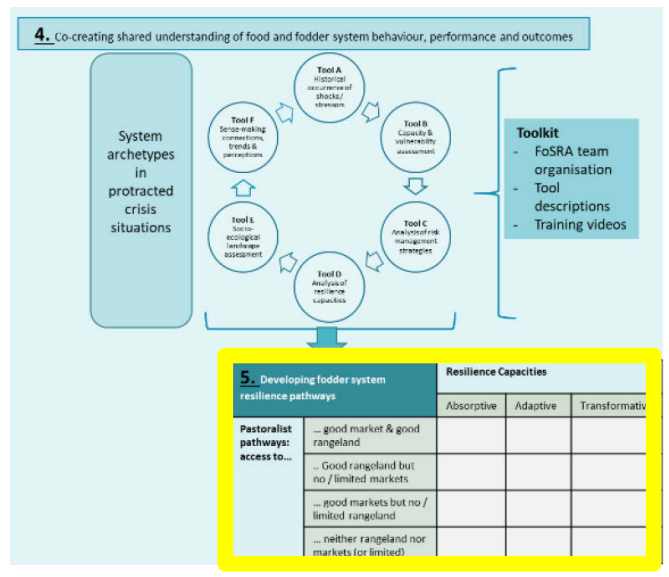
influence of the policy maker, implementor and local communities.

Prioritisation can be done based on a qualitative assessment of costs versus expected systemic change, increased fodder system resilience capacities, and projected FNS outcomes (based on scenario planning).

\section{$5.1 \quad$ Identify leverage points}

Once key challenges in fodder systems have been defined, leverage points ${ }^{22}$ are identified to strengthen the resilience of food systems and subsequent food system outcomes. A leverage point is a place/characteristic in a system where a small shift in one factor or process can contribute significantly to building fodder system resilience.

How to collect data

- Deskwork

- Interactive / participatory work with local stakeholders and community groups (KII, FGDs).

\subsection{Define spheres of influence}

Understanding the food-fodder systems, their dynamics and resilience capacities is not sufficient to define actions. Understanding the dynamics of power and influence of actors is equally required for developing effective pathways to strengthening fodder system and overall food system resilience.

Understanding the stakeholders' domain, and identifying those that can activate leverage points, is a key element in the design of effective systems pathways.

How to collect data

- Deskwork

- Interactive / participatory work with local stakeholders and community groups (KII, FGDs).

22 Based on: 'Leverage Points: Places to Intervene in a System' by Donella Meadows: http://donellameadows.org/archives/leverage-points-places-to-intervene-in-a-system/ 


\section{PART III - LEARNING \& KNOWLEDGE MANAGEMENT}

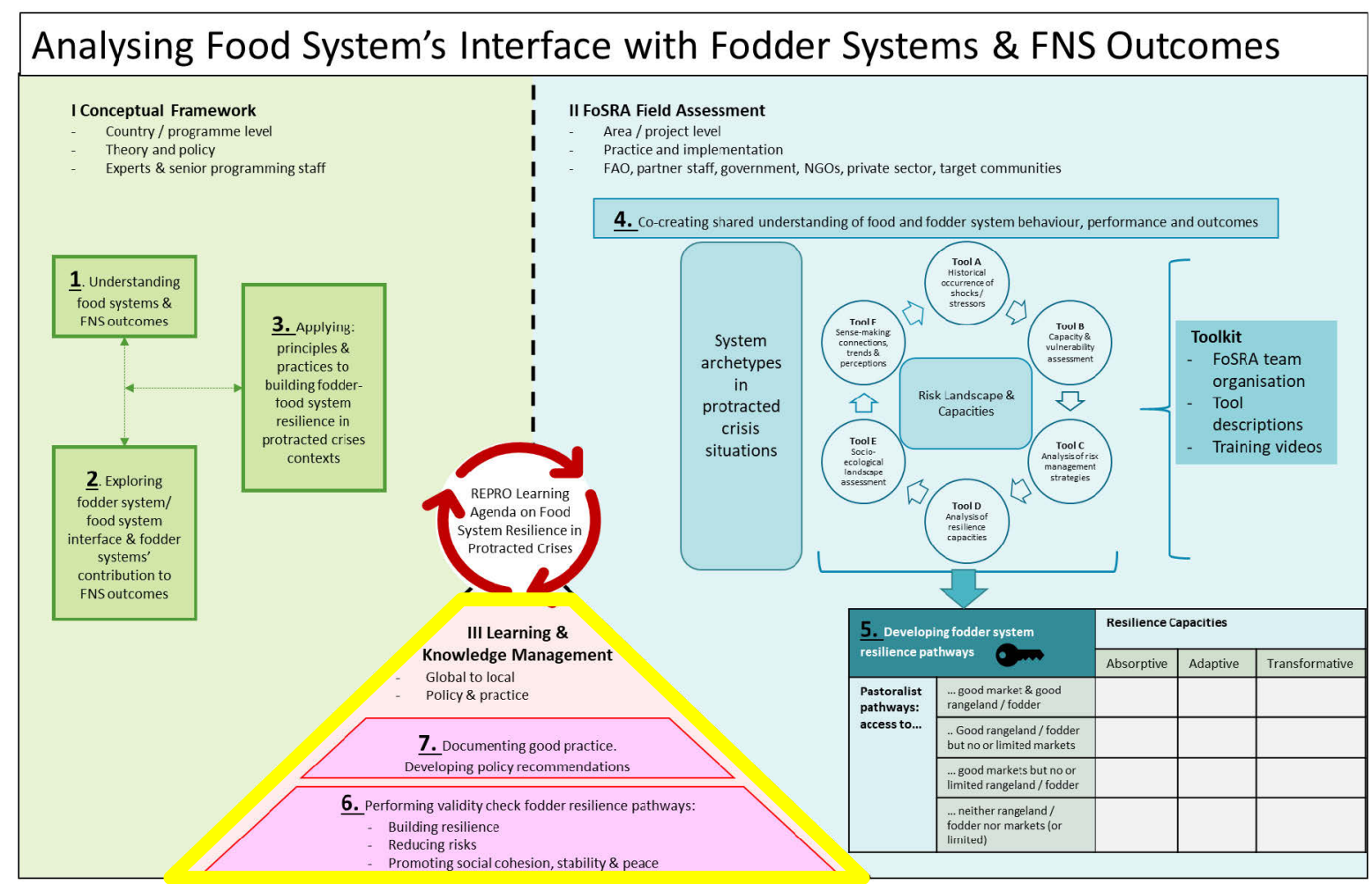

Part III represents how the first two parts can be combined in a final validation, learning and knowledge management step. Validation against resilience principles and nexus thinking is introduced, followed by a conversation that aims to document good practices and to provide policy recommendations.

It is explained how the result of the assessment has multiple values in that it can support learning at a global level (for example through the Global Network Against Food Crises or its connection to UNSCR2417) while simultaneously informing the local programming in the target area in an evidence-based, adaptive manner. 


\section{Component: Validate Specific Resilience Pathways}

Output: Validate resilience system pathways to ensure that they contribute to sustainable and resilient FNS outcomes.

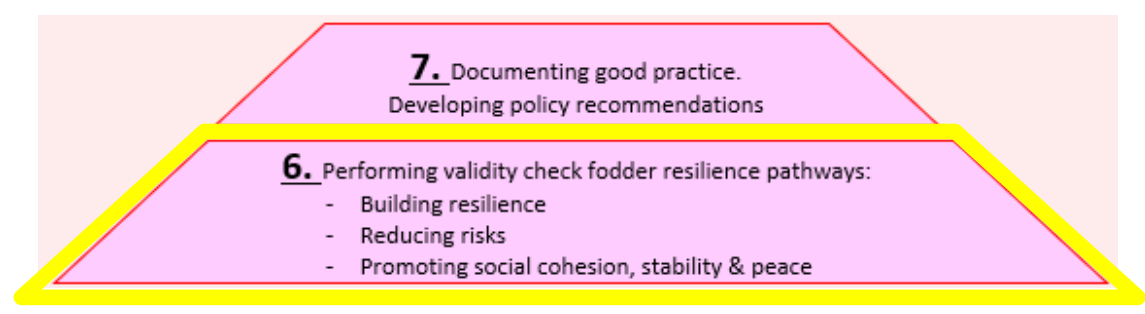

\subsection{Various Potential Validation Approaches}

This paper is a working document, and this section is still in the process of improvement and testing. It is still not decided if the validation will be specifically focussed on fodder systems or take a more holistic view on food systems and their outcomes. The validation process could take one of the following three shapes:

a. A set of characteristics. A list of characteristics of resilient food systems and communities will be generated on the basis of Twigg's characteristics of a disaster resilient community (Twigg, 2009) and the extension of his work that further included conflict-sensitivity by including 'safe' and resilient communities into the frame (Da Silva, et al., 2011). The newly created set of characteristics will extensively describe the ideal setting of what a resilient and safe community and food system in protracted crises situations would look like. The key aspects are flexible and can be selected according to their relevance in the local context.

b. A nexus question list. This includes key questions to ask from a humanitarian, developmental and peacebuilding perspective to ensure that all silos are considered when looking at the findings of the previous components of the document. Hence, the identified resilience pathways would be questioned to ensure that programming ensures long-term sustainability from all angles.

c. A modified version of testing seed system approaches. This option is based on Subedi and Vernooy (2019)'s work on seed systems but was adapted and made relevant to fodder systems. The following sections - 6.1.1 Criteria for resilience in food systems, 6.1.2 Criteria for reduced vulnerability in food systems and 6.1.3 Food System's contribution to social cohesion, peace, and stability - explain this option in further depth since this one has been developed already. However, this does not mean that this option is more valid than the others, it solely reflects REPRO's current stage of working progress.

\subsubsection{Criteria for resilience in food systems}

A proposed fodder system pathway must meet several criteria based on research and experience in order to be resilient. Subedi and Vernooy's (2019) ${ }^{23}$ concepts on seed systems were adapted to match fodder systems as well. According to this, a resilient fodder system:

- relies on the ability of fodder system actors to absorb disturbances, regroup, or reorganize, and adapt to shocks and stressors

- results from multiple fodder and knowledge interactions and continuous learning among fodder system actors and related institutions

- is demand-driven and responsive to differentiated needs and interests, supporting all users and farming systems

- recognizes, respects, and supports the key roles played by women farmers as fodder custodians, managers, networkers, and entrepreneurs.

23 Based on 'Healthy food systems require resilient seed systems': https://cgspace.cgiar.org/handle/10568/105871 


\subsubsection{Criteria for reduced vulnerability in food systems}

The following criteria, adapted from the seed system theory, will be applied (Vernooy, 2019):

- ensuring access to fodder in terms of preference, affordable price and availability when needed

- ensuring availability in terms of production and distribution

- guaranteeing fodder quality in terms of adaptability, safety, and longevity

- guaranteeing fodder choice and diversity

\subsubsection{Food systems' contribution to social cohesion, peace, and stability}

Developing local fodder system pathways in fragile and conflict affected contexts can be instrumental in sustaining peace $(F A O, 2018)^{24}$. In praxis this means a focus on social cohesion as a pathway to positive local collective action, for instance through providing equitable access to fodder.

In promoting the contribution of fodder systems to peace and stability, FAO recommends the following:

- Invest in better understanding of the local context and sequence interventions, such as designing peacebuilding and agricultural development strategies in a complementary manner; that is, beyond conflict sensitivity, into active analysis and collaboration.

- The focus should be on locally owned action rather than external actors. Peacebuilding in this context involves the restoration of a network of relationships or new arrangements for inclusive and participatory governance.

- Set examples that demonstrate a shift in approach; that is, away from focusing on risks, to one highlighting opportunities. 


\section{Component: Policy and Practice}

Output: Documentation of good practice and formulation of policy recommendations for all suitable levels and insights for adaptive REPRO

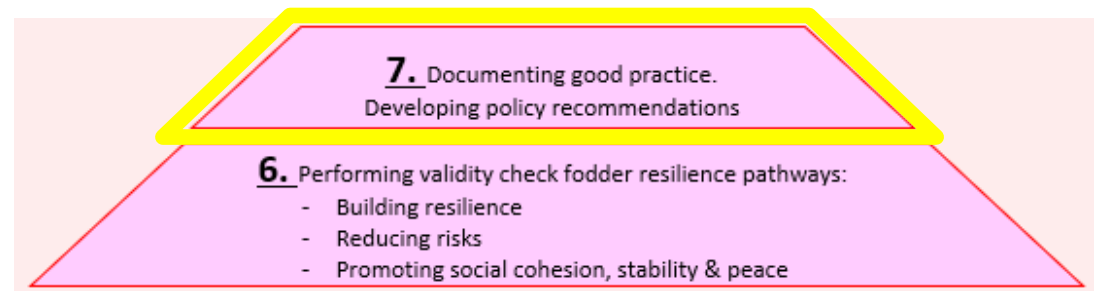
programming.

This step brings together the insights of the assessment, the local level actions and the global.

Policy recommendations can cover all suitable levels, from regional / national governments to the Global Network Against Food Crises ${ }^{25}$.

The same applies for documenting good practices, contributing to the creation of an evidence-base of approaches that worked in specific protracted crisis contexts for pastoralist or fodder systems and their interface with the overall local food system.

Good practices can relate to food system resilience in general, or to fodder systems and their interface with food systems.

Questions that can help in this step are:

- What were the most insightful learnings of the assessment/ action?

- How should these learnings be documented to create a reliable evidence base for future programmes and governance decisions?

- Are policies and practices logically aligned or support each other?

- Are there goals between policy and desirable practice?

- How can policies adapted to reinforce good practices?

- How can these insights be useful in other contexts in the region or even globally?

Insights can further be used to inform the design and strategy of programmes that aim to build resilient food systems by targeting the underpinning fodder systems.

25 http://www. fightfoodcrises.net/ 


\section{References}

Mary B Anderson and Peter J Woodrow [1989] (1998) Rising from the Ashes: Development Strategies in Times of Disaster. London: IT Publications.

Béné, C. Godfrey Wood, R. J Newsham, A. 2012. Resilience: New Utopia or New Tyranny? Reflection About the Potentials and Limits of the Concept of Resilience in Relation to Vulnerability Reduction Programmes. IDS Working Paper 405, pp 20.

https://onlinelibrary.wiley.com/doi/epdf/10.1111/j.2040-0209.2012.00405.x

Berkum, S. van, J. Dengerink and R. Ruben (2018) The food systems approach: sustainable solutions for a sufficient supply of healthy food. Wageningen Economic Research, Memorandum 2018-064. https://research.wur.nl/en/publications/the-food-systems-approach-sustainable-solutions-for-asufficient-

Bujones A., Jaskiewicz, K., Linakis, L. \& McGirr, M. 2013. A Framework for Analyzing Resilience In Fragile and Conflict-Affected Situations. USAID Final Report. Columbia University SIPA 2013. https://www.sipa.columbia.edu/academics/capstone-projects/framework-analyzing-resiliencefragile-and-conflict-affected-situations

Catley, A., Lind, J., \& Scoones, I. (2013). Development at the Margins, Pastoralism in the Horn of Africa. In A. Catley, J. Lind, \& I. Scoones, Pathways to Sustainability: Pastoralism and Development in Africa: Dynamic Change at the Margins (pp. 1-24). Earthscan Routledge.

Dengerink, J., H. Posthumus, B. de Steenhuijsen-Piters and S. Vellema, 2018. A decision-support tool for the design of food and nutrition security programming. Bridging concept and practice in the Food System approach. https://edepot.wur.nl/478040

FAO, 2018. Farmer seed systems and sustaining peace. Rome. 52 pp. Licence: CC BY-NC-SA 3.0 IGO. http://www.fao.org/3/ca1793en/CA1793EN.pdf

FAO, 2013. Resilient Livelihoods - Disaster Risk Reduction for Food and Nutrition Security Framework Programme. http://www.fao.org/3/a-i3270e.pdf

FSIN, 2014. A Common Analytical Model for Resilience Measurement: Causal Framework and Methodological Options. Resilience Measurement Technical Working Group, Technical Series No. 2, Food Security and Information Network. https://www.fsnnetwork.org/common-analytical-modelresilience-measurement-causal-framework-and-methodological-options

Global Panel. (2016). Food systems and diets: Facing the challenges of the 21st century. London: Global Panel on Agriculture and Food Systems for Nutrition.

HLPE. (2014). Food losses and waste in the context of sustainable food systems. A report by the High Level of Experts on Food Security and Nutrition of the Committee on World Food Security. Rome.

HLPE. (2017). Nutrition and food systems. A report by the High Level of Experts on Food Security and Nutrition of the Committee on World Food Security. Rome.

Maani, K.E. and R.Y. Cavana (2007). Systems thinking, systems dynamics: managing change and complexity (2nd Edition). Prentice Hall, Auckland, New Zealand.

Macrae J, and A. Harmer, 2004. Beyond the continuum: The changing role of aid policy in protracted crises. HPG Report 18. London: Overseas Development Institute.

https://www.odi.org/sites/odi.org.uk/files/odi-assets/publications-opinion-files/279.pdf

Maxwell. D, Russo. L, Alinovi. L. Constraints to addressing food insecurity in protracted crises (2011). Published by NCBI: https://www.ncbi.nlm.nih.gov/pmc/articles/PMC3411957/

Meadows, D. (1999). Leverage Points: Places to Intervene in a System. The Sustainability Institute, 2-19.

Ministry of National Planning and Development (2017). The National Development Plan (2017-2021). Ministry of National Planning and Development, Republic of Somaliland. Pp.326

Mock., N., Béné, C., Constans, M and Frankerberger, T (2015). Systems Analysis in the Context of Resilience. FSIN technical series 6.

https://www.researchgate.net/publication/282575135_Systems_Analysis_in_the_Context_of_Resil ience 
Nguyen, N.C. and O.J.H. Bosch (2012). A Systems Thinking Approach to identify Leverage Points for Sustainability: A Case Study in the Cat Ba Biosphere Reserve, Vietnam. In: Systems Research and Behavioural Science 30: 104-115.

Subedi, A. and R. Vernooy, 2019. Healthy food systems require resilient seed systems. Agrobiodiversity Index Report 2019 - Risk and Resilience. Bioversity International.

https://cgspace.cgiar.org/bitstream/handle/10568/105871/ABDI_Healthy\%20food\%20systems\%2 Oresilient\%20seed\%20systems\%20(1).pdf

Twigg, J., 2009. Characteristics of a disaster-resilient community: a guidance note (version 2). 2 November 2009.

https://www.researchgate.net/publication/305615592_Characteristics_of_a_disasterresilient_community_a_guidance_note_version_2

Vasilescu, L. Khan, A. Khan, H. Disaster Management Cycle, A Theoretical Approach. 2008. Editura Universitaria Craiova, pp 43-50.

Westhoek, H., Ingram, J., Van Berkum, S., Özay, L., \& M., H. (2016). Food Systems and Natural Resources. A Report of the Working Group on Food Systems of the International Resource Panel. UNEP.

Waithanji, E,. Saeed, K., Kennedy, T., Yusuf, H., Nur, A., Warsame, A., Mbugua, E., and Hersi, N 2020. Food and Nutrition Security Resilience Programme (FNSREPRO): Building food system resilience in protracted crises. Report of The Multi-Disciplinary Context and Fodder Value Chain Analysis in Sool And Sanaag (Somaliland). FAO April 2020

Zselenczky, L and Yosef, S (2014). Are shocks becoming more frequent or intense? INTERNATIONAL FOOD POLICY RESEARCH INSTITUTE (IFPRI). https://www.ifpri.org/publication/are-shocks-

becoming-more-frequent-or-intense 
APPENDICES 


\section{Appendix 1 Toolbox}

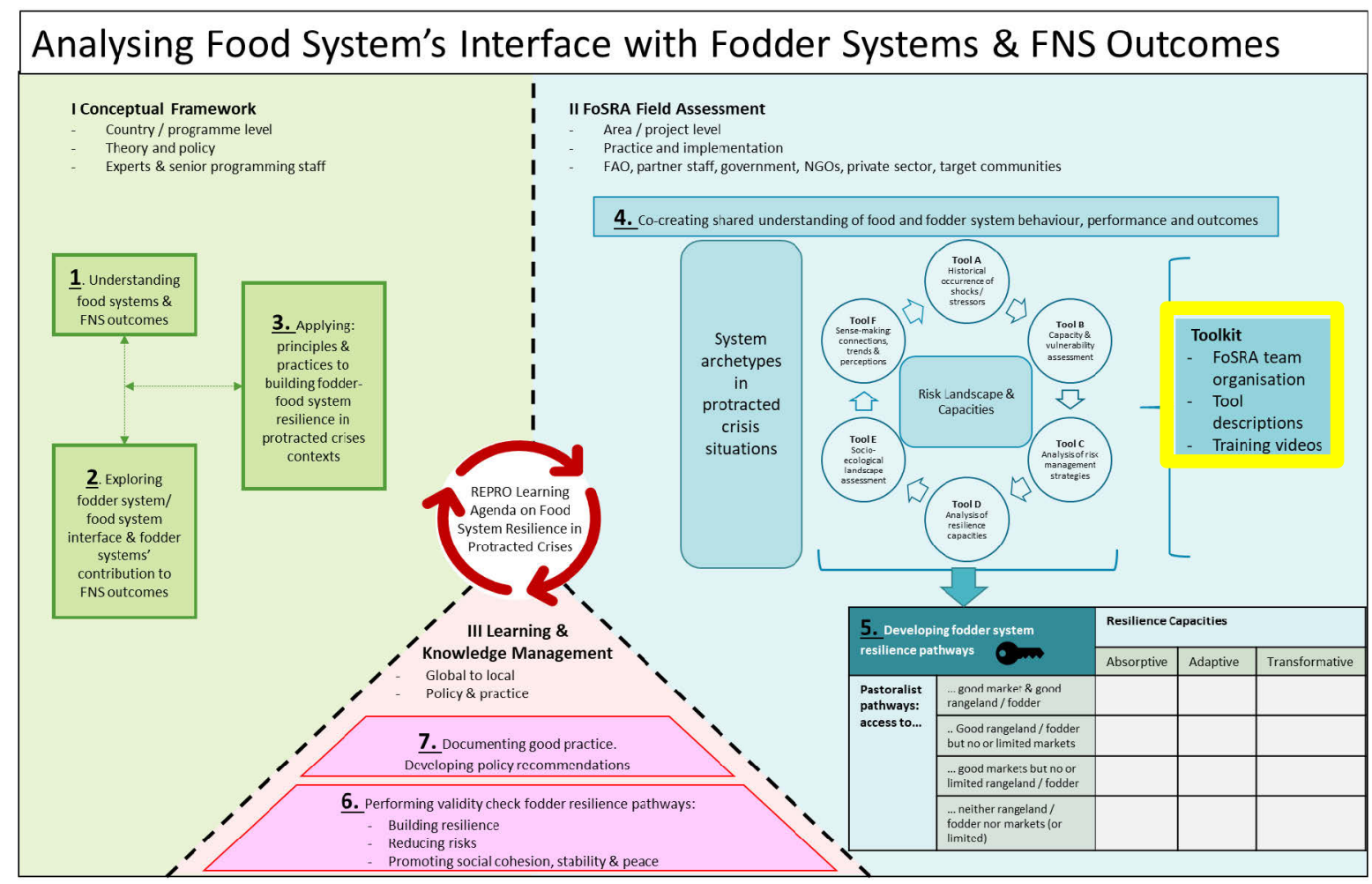

Appendix 1, the Toolbox, is the practical element of part II since it details tool descriptions and respective facilitation guides. Furthermore, it includes training presentations, training videos and other practical information that inform how the tools can be used best to gather information. 


\section{A1 Building local capacity for undertaking the FoSRA}

FoSRA training PowerPoints have been developed to support and facilitate capacity building workshops for undertaking FoSRA data collection under FNS-REPRO in Somaliland (February \& September 2020) and Sudan (October 2020).

The FoSRA training PowerPoints are developed to match each country's thematic focus, fodder and Gum Arabic, and are continuously updated and improved. As such, the materials are to be seen as a work in progress.

The PowerPoints can be accessed on Google Drive through the following link:

https://drive.google.com/drive/folders/1PZtSYZv03bRHM3W1r8jdaCeL_Dyq7AQe?usp=sharing 


\section{A2 Employing the FoSRA tools}

This component provides an in-depth explanation of the different, recommended tools to undertake the FOSRA.

The tools are organized in six steps that, in combination, analyse how shocks and stressors impact the local food system with a specific focus point on the interface of the selected target system (fodder system) and the FNS outcomes. The tools generate insights for designing appropriate and effective context specific interventions to strengthen food system resilience:

- Tool a) Identifying shocks and stressors over time and their impacts on livelihoods

- Tool b) Identifying existing capacities and vulnerabilities in face of shocks and stressors

- Tool c) Comprehending existing risk management strategies facing shocks and stressors

- Tool d) Understanding prevailing resilience capacities to deal with shocks and stressors

- Tool e) Understanding dynamics and interactions between the natural environment and human activities

- Tool f) Sense-making: connections, trends, and perceptions

Each step results in a report, produced by the facilitators, that synthesises the information gained from all the workshops and outlines possible actions. This is a strong basis for the following component of the assessment; developing pathways that enable farmers in protracted crises to increase resilience in fodder systems, thus underpinning food system performance and improved FNS outcomes.

Tool A: Historical Timeline of Shocks \& Stressors

Purpose: to identify recurring shock/stressors in geographic target areas which occurred in the last 10 years looking at frequency and impact.

Through: a focus group discussion with 6-10 (male, female, youth and/or mixed) local representatives of predominant livelihood groups (i.e. farmers, pastoralists), target communities, elders and youths.

By: facilitating a participatory discussion capturing local knowledge and understanding by drawing a historical timeline of shocks and stressors on a flip chart with markers.

Duration: approximately 45 minutes.

\section{Tool B: Vulnerabilities \& Capacities in Face of Shocks \& Stressors}

Purpose: to identify livelihood capacities and vulnerabilities of target communities / livelihood groups at 'one point in time' in the face of a shock and/or stressor.

Through: a focus group discussion with 6-10 (male, female, youth and/or mixed) local representatives of predominant livelihood groups (i.e. farmers, pastoralists), target communities, elders and youths.

By: facilitating a participatory discussion capturing local knowledge and understanding by drawing a historical timeline of shocks and stressors on a flip chart with markers.

Duration: approximately 45 minutes.

\section{Tool C: Risk Management Strategies facing Shocks \& Stressors}

Purpose: to identify and understand risk management strategies that are present in target communities / livelihood groups, in the face of recurring and impacting shocks/stressors in geographic target areas.

Through: a focus group discussion with 6-10 (male, female, youth and/or mixed) local representatives of predominant livelihood groups (i.e. farmers, pastoralists), target communities, elders and youths. 
By: facilitating a participatory discussion capturing local knowledge and understanding by drawing and filling in a risk management strategies table making use of a flip chart and markers.

Duration: approximately 45 minutes.

\section{Tool D: Resilience Capacities \& Strategies facing Shocks \& Stressors}

Purpose: to identify resilience capacities of target communities / livelihood groups for building/strengthening resilience of livelihoods in the face of shocks/stressors.

Through: a focus group discussion with 6-10 (male, female, youth and/or mixed) local representatives of predominant livelihood groups (i.e. farmers, pastoralists), target communities, elders and youths.

By: facilitating a participatory discussion capturing local knowledge and understanding by drawing and filling in a resilience capacities table making use of a flip chart and markers.

Duration: approximately 45 minutes.

\section{Tool E: Socio-Ecological Landscape Assessment}

Purpose: understanding the interconnections of the natural environment and socio-economic aspects to local communities (in order to ensure long-term sustainability and governance dynamics that determine land access etc.)

Through: a community and individual scoring process to map perceptions of changes in socioeconomic landscape dynamics and trends vis-à-vis development of livestock pathways

By: $\quad$ facilitating a community workshop and discussion

Duration: approximately half a day

\section{Tool F: Key Informant Interview Format}

Purpose: mapping perceptions on change and its implications for food system resilience programming, deepening understanding on critical elements for food system resilience programming that are discovered in tool $1-4$.

Through: stories of Change with key informants including: local community leadership, representatives of key ministries, relevant private sector actors, NGO and other international organisation staff.

By: facilitating a qualitative and in-depth discussion with a key-informant.

Duration: approximately 1.5 hours.

\footnotetext{
In summary

Together, the six steps and tools therein described above provide a thorough and effective method of analysing food systems and their specific target points at a local and state level and form a robust basis for developing intervention pathways that will contribute to their system resilience.

Moreover, the analysis itself increases resilience as local farmers and other stakeholders by taking part in a process to co-create understanding of fodder systems and food system behaviour create a foundation to implementing commonly agreed upon resilience system pathways.
} 


\section{A3 FoSRA Tools' Facilitation Guides}

\section{FoSRA Tool a: Historical Timeline of Shocks and Stressors}

\section{Why Assessing the History of Shocks and Stressors?}

Purpose: Identification and prioritization of shocks \& stressors

A resilience approach acknowledges the need to measure shocks and stressors within complex systems and over extended periods of time ${ }^{26}$ (Mock et al., 2015) ${ }^{27}$. To identify recurring shock and stressors (hazards) in REPRO target areas which occurred in the last 10 years and considering impacts, is the starting point for gaining an understanding on critical food system behaviour in face of shocks and stressors.

In the field of development, shocks have been defined as "external short-term deviations from longterm trends, deviations that have substantial negative effects on people's current state of well-being, level of assets, livelihoods, or safety, or their ability to withstand future shocks" (Zseleczky and Yosef, 2014) $)^{28}$.

In contrast, stressors are long-term pressures (e.g. degradation of natural resources, urbanization, political instability or diminishing social capital) that undermine the stability of a system (i.e. political, security, economic, social or environmental) and increase vulnerability within it (Bujones et al., 2013 $)^{29}$.

Communities often face a wide variety of hazards. Each hazard has its own unique impact and thus, one needs to identify which hazard occurs most frequently and/or has the most severe impact on the livelihoods of people in target areas in order to formulate strategies to address the impact.

The nature of protracted crises is that they are long-term and cannot be understood without looking into the past - its impacts are long-term and develop over time. One can learn lessons by exploring the pasts these crises develop over time scales and spaces.

To address hazard impacts in a protracted setting, it is useful to regard them in their interaction and sequence to each other, gaining a deeper understanding of the risks faced by the community.

Identified hazards have to be prioritized in order to further define which shocks and stressors are to be explored sequential in tools 2,3 and 4 .

26 See also FSIN Technical Paper 2. Resilience is to be observed at a given point in time and over extended periods because the effects of resilience capacity are path-dependent and time-sensitive (FSIN Technical paper2; p13).

27 Systems Analysis in the Context of Resilience:

https://www.researchgate.net/publication/282575135_Systems_Analysis_in_the_Context_of_Resilience

28 Are Shocks becoming More Frequent or Intense?: https://www.ifpri.org/publication/are-shocks-becoming-morefrequent-or-intense

29 A FRAMEWORK FOR ANALYZING RESILIENCE IN FRAGILE AND CONFLICT-AFFECTED SITUATIONS, USAID: https://www.sipa.columbia.edu/academics/capstone-projects/framework-analyzing-resilience-fragile-and-conflictaffected-situations 


\section{HoW to Assess the History of Shocks and Stressors?}

Through: a focus group discussion with 6-10 (male, female, youth and/or mixed) local representatives of predominant livelihood groups (i.e. farmers, pastoralists), target communities, elders and youths

By: facilitating a participatory discussion capturing local knowledge and understanding by making use of a flip chart and markers

Duration: approximately 45 minutes

Use: sheet A1 or a flipchart for filling in the timeline

\section{Steps to Follow}

Ask the groups to draw a disaster (shocks and stressors) timeline (see figure....) and answer the questions below:

Step 1: Identifying shocks and stressors having occurred over the last 10 years

- Make a clear difference between 'shock' and 'stressor'

- Note down a top $\mathbf{3}$ according to frequency and make a top $\mathbf{3}$ according to impact with a historical timeline on sheet $\mathrm{A} 1$ or on a flipchart

Step 2: Identifying impact of shocks and stressors

- What are $\mathbf{3}$ key impacts of the most impactful shock or stressor on your livelihood?

> Key impact 1 (most important):

$>$ Key impact 2 ( $2^{\text {nd }}$ most important):

> Key impact 3 ( $3^{\text {rd }}$ most important):

Step 3: Discussion - most worrying shock or stressor

- Which shock or stressor do you worry about the most and why? Please explain clearly.

- Mention and describe $\mathbf{3}$ most important aspects from most worrisome to least worrisome.

Most important shock or stressor that you worry about:

Reason 1 (most important):

> Reason 2 (2nd most important):

> Reason 3 (3rd most important):

Use the most worrying shock or stressor that is identified here in the following exercises 2- 4 . 


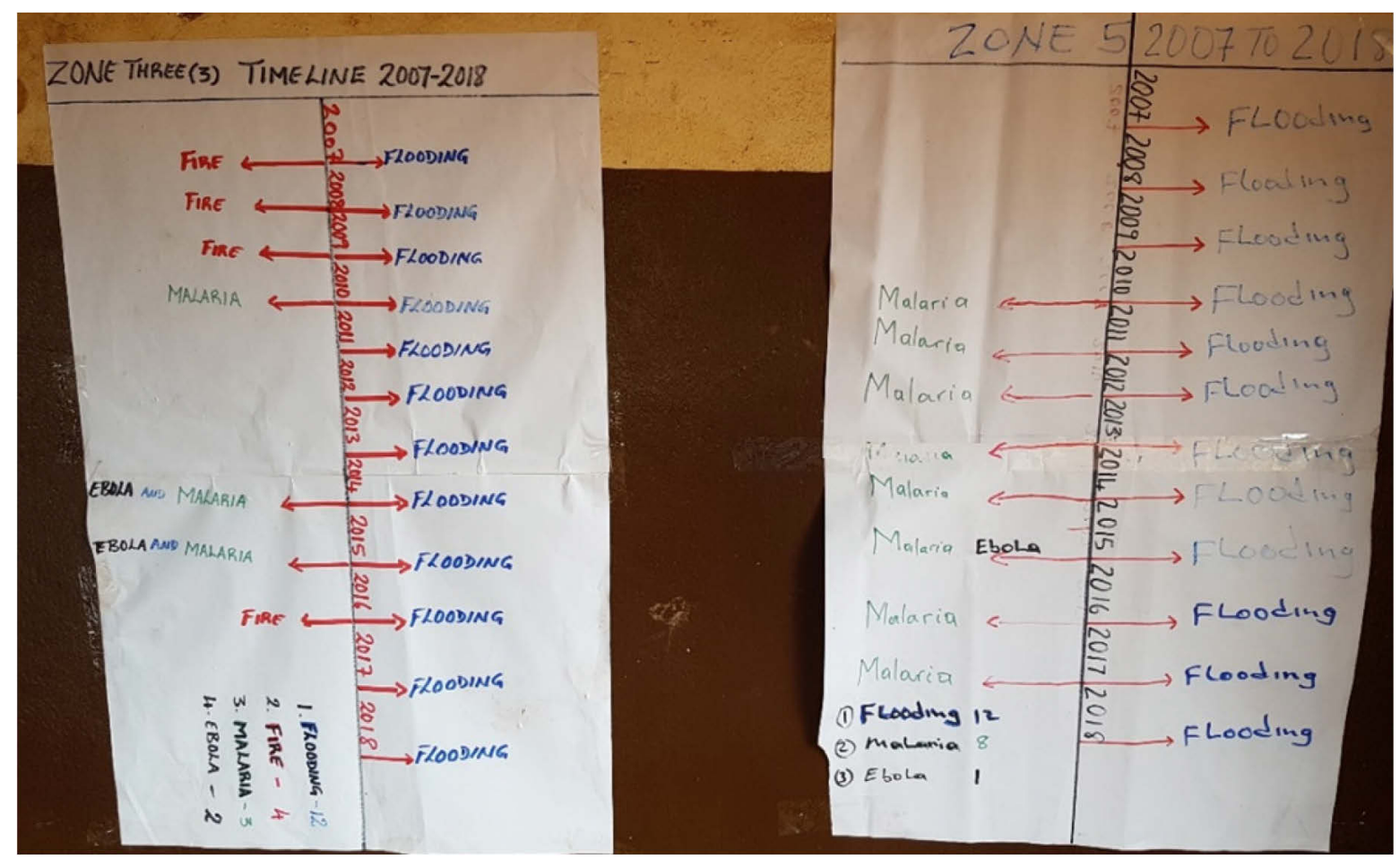

Figure 6 Example of a disaster timeline (Source: Eelke Boerema). 


\section{Disaster Timeline Sheet}

\begin{tabular}{|c|c|c|}
\hline Year & Shock & Stressor \\
\hline \multirow[t]{3}{*}{2020} & Rank 1) & Rank 1) \\
\hline & Rank 2) & Rank 2) \\
\hline & Rank 3) & Rank 3) \\
\hline \multirow[t]{3}{*}{2019} & Rank 1) & Rank 1) \\
\hline & Rank 2) & Rank 2) \\
\hline & Rank 3) & Rank 3) \\
\hline \multirow[t]{3}{*}{2018} & Rank 1) & Rank 1) \\
\hline & Rank 2) & Rank 2) \\
\hline & Rank 3) & Rank 3) \\
\hline \multirow[t]{3}{*}{2017} & Rank 1) & Rank 1) \\
\hline & Rank 2) & Rank 2) \\
\hline & Rank 3) & Rank 3) \\
\hline \multirow[t]{3}{*}{2016} & Rank 1) & Rank 1) \\
\hline & Rank 2) & Rank 2) \\
\hline & Rank 3) & Rank 3) \\
\hline \multirow[t]{3}{*}{2015} & Rank 1) & Rank 1) \\
\hline & Rank 2) & Rank 2) \\
\hline & Rank 3) & Rank 3) \\
\hline \multirow[t]{3}{*}{2014} & Rank 1) & Rank 1) \\
\hline & Rank 2) & Rank 2) \\
\hline & Rank 3) & Rank 3) \\
\hline \multirow[t]{3}{*}{2013} & Rank 1) & Rank 1) \\
\hline & Rank 2) & Rank 2) \\
\hline & Rank 3) & Rank 3) \\
\hline \multirow[t]{3}{*}{2012} & Rank 1) & Rank 1) \\
\hline & Rank 2) & Rank 2) \\
\hline & Rank 3) & Rank 3) \\
\hline \multirow[t]{3}{*}{2011} & Rank 1) & Rank 1) \\
\hline & Rank 2) & Rank 2) \\
\hline & Rank 3) & Rank 3) \\
\hline \multirow[t]{3}{*}{2010} & Rank 1) & Rank 1) \\
\hline & Rank 2) & Rank 2) \\
\hline & Rank 3) & Rank 3) \\
\hline \multirow[t]{3}{*}{ Top } & Rank 1) & Rank 1) \\
\hline & Rank 2) & Rank 2) \\
\hline & Rank 3) & Rank 3) \\
\hline
\end{tabular}




\section{FoSRA Tool b: Capacity and Vulnerability Assessment}

\section{Why Assessing Capacities and Vulnerabilities?}

Purpose: to identify livelihood capacities and vulnerabilities at 'one point in time' in the face of a shock and/or stressor.

This exercise identifies vulnerabilities and capacities of groups, communities, individuals, or livelihoods in face of a specific shock or stressor. The basis of the CVA framework, as described in by Anderson and Woodrow ${ }^{30}$, is a simple matrix for viewing people's vulnerabilities and capacities in four broad, interrelated areas: physical/material, social/organisational, motivational/attitudinal and political/institutional ${ }^{31}$ (see Figure 3). Vulnerability is composed of different interrelating factors along these four dimensions. On the other hand, groups, communities, individuals or livelihoods typically have capacities that can address these vulnerabilities in order to reduce risk for disasters.

\section{How to Assess Capacities and Vulnerabilities?}

Through: a focus group discussion with 6-10 (male, female, youth and/or mixed) local representatives of predominant livelihood groups (i.e. farmers, pastoralists), target communities, elders and youths

By: facilitating a participatory discussion capturing local knowledge and understanding by making use of a flip chart and marker

Duration: approximately 45 minutes

Use: sheet $A 2$ or a flipchart for filling in the CVA

\section{Steps to Follow}

Step 1: Identification of capacities and vulnerabilities in the face of shocks and stressors

- Use CVA table on sheet A2 identify vulnerabilities and capacities of your community or livelihood group in the face of the most impactful shock/stressor which was identified in tool 1

- Describe in the top left of the table which shock/stressor is examined and describe capacities and vulnerabilities in face of this shock or stressor in the CVA table on sheet A2 or on a flipchart

\begin{tabular}{|c|c|c|}
\hline Shock or Stressor: Drought & Vulnerabilities & Capacities (what is in place) \\
\hline $\begin{array}{l}\text { Physical/material (what productive } \\
\text { resources, skills, and hazards exists?) }\end{array}$ & $\begin{array}{l}\text { Lack of proper infrastructure such as bridges, dams, } \\
\text { water piping. Lack of financial resources }\end{array}$ & $\begin{array}{l}\text { Simple technology for warning systems, Improved } \\
\text { distribution of water gauges }\end{array}$ \\
\hline $\begin{array}{l}\text { Social/Organisational (what are the } \\
\text { relations and organization among } \\
\text { people?) }\end{array}$ & $\begin{array}{l}\text { Unwillingness to leave, Bottom up approach to risk, } \\
\text { Socio-economic restraints force them to stay }\end{array}$ & $\begin{array}{l}\text { Social cohesion, cooperation between scientists and } \\
\text { communities, awareness of present risk }\end{array}$ \\
\hline $\begin{array}{l}\text { Motivational/Attitudinal (how does } \\
\text { the group/community view its ability } \\
\text { to change?) }\end{array}$ & $\begin{array}{l}\text { Religious and cultural restraints prevent affected from } \\
\text { acting }\end{array}$ & $\begin{array}{l}\text { Recognition of the need of community } \\
\text { involvement. Increased awareness and willingness to } \\
\text { reduce risk }\end{array}$ \\
\hline $\begin{array}{l}\text { Political/Institutional (what are } \\
\text { political/institutional capacities or } \\
\text { vulnerabilities?) } \\
\text { (Political is optional, depending on the } \\
\text { level of political sensitivities in the } \\
\text { context) }\end{array}$ & $\begin{array}{l}\text { Institutional action mainly focussed around relief, } \\
\text { Dissonance between responsibilities of local } \\
\text { government and their actions, responsible for } \\
\text { evacuations but delegating that responsibility to civil } \\
\text { society }\end{array}$ & $\begin{array}{l}\text { Civil society organisations and community } \\
\text { representatives take on a large role in risk reduction, } \\
\text { organizing evacuation, warning and informing } \\
\text { communities of risk and onset. }\end{array}$ \\
\hline
\end{tabular}

\section{Figure 7 Example of a CVA table.}

30 The CVA is described in detail in Anderson' and Woodrow's 'Rising from the Ashes' (1989).

31 A fourth dimension was added to the CVA exercise, namely political/institutional, by the authors of this report to make the CVA more sensitive for assessments in contexts of protracted crises. 


\begin{tabular}{|c|c|c|}
\hline Describe Shock / Stress: & Vulnerabilities & Capacities \\
\hline $\begin{array}{l}\text { Physical/material (what productive } \\
\text { resources, skills, and hazards exists?) } \\
\text { e.g. environmental degradation, unsafe/safe } \\
\text { infrastructure }\end{array}$ & 1) & $\begin{array}{l}\text { 1) } \\
\text { 2) } \\
\text { 3) }\end{array}$ \\
\hline $\begin{array}{l}\text { Social/Organisational (what are the } \\
\text { relations and organization among people?) } \\
\text { e.g. level of education, presence of social } \\
\text { safety nets, vulnerable livelihoods, }\end{array}$ & 1) & 1) \\
\hline $\begin{array}{l}\text { Motivational/Attitudinal (how does the } \\
\text { group/community view its ability to } \\
\text { change?) } \\
\text { e.g. community's view of its ability to create } \\
\text { change }\end{array}$ & 1) & $\begin{array}{l}\text { 1) } \\
\text { 2) } \\
\text { 3) }\end{array}$ \\
\hline $\begin{array}{l}\text { Political/Institutional (structures, } \\
\text { decision-making processes, power relations } \\
\text { affecting responses) } \\
\text { (Political is optional, depending on the level } \\
\text { of political sensitivities in the context) }\end{array}$ & 1) & $\begin{array}{l}\text { 1) } \\
\text { 2) }\end{array}$ \\
\hline
\end{tabular}




\section{FoSRA Tool c: Risk Management Strategies}

\section{Why Analysing Risk Management Strategies?}

Purpose: to identify and understand risk management strategies that are existing in communities/localities/livelihood groups. Following the rationale of the Disaster Risk Management Cycle (DRMC), risk management strategies are proposed along four interrelated phases; preparation, mitigation, response and recovery ${ }^{32}$, in the face of recurring and impacting shocks/stressors. For REPRO's purpose, the 'response' phase is replaced with 'coping' strategies ${ }^{33}$.

This tool is applied in REPRO programme areas, with the purpose to determine to what extent do communities, individuals, households, livelihood groups:

- prepare for impacts from shock/stressor

- mitigate the negative effects from a shock/stressor (before or during)

- cope with negative effects while it is happening

- recover from a disaster after it has happened

\section{How to Analyse Risk Management Strategies?}

Through: a focus group discussion with 6-10 (male, female, youth and/or mixed) local representatives of predominant livelihood groups (i.e. farmers, pastoralists), target communities, elders and youths.

By: facilitating a participatory discussion capturing local knowledge and understanding by making use of a flip chart and markers.

Duration: approximately 45 minutes.

Use: sheet A3 or a flipchart for filling in Risk Management Strategies.

\section{Steps to Follow}

\section{Step 1: Discussion - identification on risk management strategies}

- Use the most impactful shocks and stressors as identified in tool $\mathbf{1}$ and $\mathbf{2}$ and ask each group to think of risk management strategies applied when dealing with this shock/stressor

- Ask each of the groups to answer the following questions related to risk management strategies in the face of the most impactful shock/stressor as identified in tool 1 and 2:

> How does your community / livelihood group / region prepare for a disaster before it happens?

- E.g. preparedness plans; emergency exercises/training; early-warning systems.

$>$ How does your community / livelihood group / region minimize (mitigate) the negative impacts of a disaster?

- E.g. building codes and zoning; vulnerability analyses; public education.

$>$ How does your community / livelihood group / region cope while they are being affected by a disaster?

- E.g. ability of people, organizations and systems, using available skills and resources, to manage adverse conditions, risk or disasters.

32 The DRMC is described in detail in; Disaster Management Cycle, a Theoretical Approach, Vasilescu et al (2008).

33 As disaster response is often relatively absent in protracted crises, a more detailed focus is given to coping strategies. 
$>$ How does you community / livelihood group / region recover from a disaster after it has happened?

- E.g. humanitarian aid, temporary housing, savings, grants, medical care.

$>$ Which of the identified factors from the above questions are done by the community/locality/livelihood groups themselves (internal) and which are done by outside actors (external)?

\section{Step 2: Describe risk management strategies in the face of a shock or stress}

- Describe in the top left of the table which shock or stressor is used and fill in the risk management strategies on sheet $A 3$ or on a flipchart

- Make a difference between 'internal' strategies, referring to risk management strategies employed by people within the community and 'external' strategies, referring to risk management strategies employed by outsiders from the community. 


\section{Sheet A3: Risk Management Strategies}

Describe the specific Shock/Stressor:

Preparedness: how to prepare for a

disaster before it happens

3) 1)

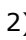

Mitigation: how to take measure to minimize negative effects of a disaste

1)
Cope: how to cope with negative effects of a Recovery: how to recover from the negative disaster when it happens

1)

2)

)

2) effects of a disaster when it happened

\section{Internal}

Perspective

(what communities

do themselves)

2)

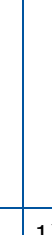

1)

2)

External

perspective

(support coming

from outside, e.g.

government or

international

organisations) 


\section{FoSRA Tool d: Resilience Capacities}

\section{Why Identifying Resilience Capacities?}

Purpose: to identify capacities for building/strengthening resilience of livelihoods in the face of shocks/stressors.

The 3-D Resilience Framework (see Figure 8), (Béné, 2012), proposes that resilience emerges as the result of three capacities: absorptive, adaptive and transformative capacities. Each capacity leads to a different outcome: persistence, incremental adjustment, or transformational responses. Building resilience involves making investments that strengthen the absorptive, adaptive and transformative capacities of vulnerable populations to cope with and recover from specific shocks and stressors.

In studying food system resilience, it is important to understand how community resilience capacities are maintained or change over time and place as a result of impacting shocks/stressors. Gaining this insight will also help to develop scenarios to invest in building community resilience.

REPRO will utilise the 3-D Resilience Framework to map resilience capacities and their outcomes across main shocks and stressors.

\section{How to Identify Resilience Capacities?}

Through: a focus group discussion with 6-10 (male, female, youth and/or mixed) local representatives of predominant livelihood groups (i.e. farmers, pastoralists), target communities, elders and youths.

By: facilitating a participatory discussion capturing local knowledge and understanding by making use of a flip chart and markers.

Duration: approximately 45 minutes.

Use: sheet A4 or a flipchart for filling in Resilience Capacities.

\section{Steps to Follow}

\section{Step 1: Discussion - identification of resilience capacities in the face of a shock or stress}

- Discuss on the existence, or absence, of resilience capacities in the community

\section{Step 2: Describe resilience capacities in the face of a shock or stress}

- The table makes a difference between capacities that are already in place $\left(1^{\text {st }}\right.$ row - existing capacities) and capacities that are missing but required ( $2^{\text {nd }}$ row - capacity gaps)

- Note down the most impactful shock or stressor which was used in tool 1-3 and fill in the Resilience Capacities Table in sheet A4 or on a flipchart

\begin{tabular}{|l|l|l|}
\hline $\begin{array}{l}\text { Absorptive capacity } \\
\begin{array}{l}\text { The capacity to withstand } \\
\text { threats and minimize } \\
\text { exposure to shocks and } \\
\text { stressors through preventative } \\
\text { measures and appropriate } \\
\text { coping strategies to avoid } \\
\text { permanent, negative impacts. }\end{array}\end{array}$ & $\begin{array}{l}\text { Adaptive capacity } \\
\text { The capacity to adapt to new } \\
\text { options in the face of crisis by } \\
\text { making proactive and } \\
\text { informed choices about } \\
\text { alternative livelihood } \\
\text { strategies based on an } \\
\text { understanding of changing } \\
\text { conditions. }\end{array}$ & $\begin{array}{l}\text { The capacity to transform the set of } \\
\text { livelihood choices available through } \\
\text { empowerment and growth, including } \\
\text { governance mechanisms, } \\
\text { policies/regulations, infrastructure, } \\
\text { community networks, and formal and } \\
\text { informal social protection mechanisms that } \\
\text { constitute an enabling environment for } \\
\text { systemic change. }\end{array}$ \\
\hline
\end{tabular}

Figure 8 The Three Resilience Capacities (FAO, 2015). 


\section{Sheet A4 Resilience Capacities}

Describe the specific Shock/Stressor:

Absorptive capacity:

Adaptive capacity:

The capacity to withstand the negative effects of

shocks/stressors through preventative measures

and appropriate coping strategies to avoid

Present capacities to withstand shock/stressor:

(in place in the community) of shocks/stressors by making informed choices
The capacity to adapt to new options in the face

about alternative livelihood strategies based on

understanding of changing conditions

Transformative capacity:

The capacity to transform the set of livelihood choices available through empowerment and growth, including government mechanisms, policies, regulations, infrastructure, networks, and formal / informal social protection mechanisms that provide an enabling environment for systemic change 
Required capacities to withstand shock/stressor
1)
1)

1)

(missing in the community) 


\section{FoSRA Tool e: Socio-ecological Landscapes}

The tool is not standalone. It will be reinforced with a link to other regional projects that align with the FNS-REPRO project -NUFFIC funded training and institutional collaboration projects- which will develop a landscape-oriented short course that will align with these topics.

\section{WHY analyse the socio-ecological landscape?}

- Important to acknowledge connections to ecological environment \& long-term sustainability, human wellbeing linked with ecological balance. Dependence on natural environment needs to be accounted for when planning sustainable food system interventions

- (Stable) access to land and resources as central to food system resilience (and awareness of existing tensions/ clashes about management of / access to the natural environment)

- Governance (formal/ informal) of resources is critical to ensure a management that supports/promotes sustainable livelihoods (also in light of climate change and resulting impacts on the usability of local landscapes over time), and peaceful living

- Diversity of natural landscapes as well as agricultural crops is tightly linked with resilience $\&$ climate action -> requires understanding of existing diversity \& it's tends

- Innovation \& knowledge transfer from women or elders determines trends in how the natural environment is used and cared for

\section{HOW should a socio-ecological landscape analysis be conducted?}

\section{General guidance}

- Group size, number of workshops, duration of sessions when implementing it, timing of day (to not interfere with their work) and resources required / available

- Who? Gender, returnees, IDP's, agro-pastoralists etc.

- Box 1 presents thematic categorise including the questions for later community scoring 
Box 1: Indicators categories including key questions, adapted from: Invalid source specified.

\section{Diversity}

1. Is the landscape composed of diverse natural ecosystems and land uses?

2. Are different local crops, varieties and animal breeds conserved and used in the community?

3. Is agricultural biodiversity and associated knowledge documented and exchanged?

\section{Governance of landscapes / natural environment}

4. Does the community have customary/formally recognized rights over land, (seasonal) pastures, water \& natural resources?

5. Is there connection, coordination and cooperation within and between communities for natural resource management?

6. Are common resources managed sustainably?

7. Are ecological interactions between different landscape components considered while managing natural resources?

\section{Accessibility \& mobility}

8. Is access to resources and subsequent livelihood opportunities fair and equitable for all community members, including women, at household, community and landscape level?

9. Are households and communities able to move around between different production activities and locations as necessary (specifically access dimensions of grazing areas and markets)?

10. Are their tensions/ clashes/ conflicts related to the management or accessibility of natural resources?

\section{Conservation practices}

11. Are any of these landscape areas (formally or informally) protected?

12. Do current community activities (for example livelihoods) impact the natural environment negatively?

13. Do current community activities (for example livelihoods) impact the natural environment positively?

Resilience of natural environment

14. Does the landscape have the ability to recover and regenerate after extreme environmental shocks (e.g. rangelands after severe droughts or floods)?

\section{Nutrition / local production \& consumption}

15 . Does the community consume a diversity of locally produced food?

\section{Innovation \& knowledge transfer}

16. Does the community develop, improve and adopt new (agricultural or conservation) practises and / or revitalises traditional ones to adapt to changing conditions, including climate change?

17. Does the community develop innovative use of the local biodiversity for its livelihoods?

18. Are local knowledge and cultural traditions related to biodiversity transmitted from elders and parents to their youth?

19. Are women's knowledge, experiences \& skills recognised and respected at household, community and landscape levels?

\section{Step 1: Building a Common Understanding of the Landscape and changes over time therein}

Introduction, participatory mapping (building of a common ground of landscape boundaries and prevalence of types of landscapes and how they changed over time, e.g. through climate change, population pressure etc.)

\section{Step 2: Clarifying Concepts: Biodiversity, Resilience}

a. Discussion of biodiversity: discuss list of examples of agricultural diversity (crops but maybe also wildlife since larger wildlife may destroy crops while others, such as bees, may be beneficial)

b. Resilience: brief discussion (if not done through prior tools \& groups may be the same) - explain resilience, explain adaption, refer to timeline of shocks/ stressors from tool a)

\section{Step 3: Explanation of Indicators \& process}

- Talk through the indicator categories, ensure that an understanding of questions is given and consistent between participants

- Explaining the scoring process itself, (individual, group), which scale (e.g. 0-10)

- Explain how trends are indicated through arrows (increasing over time, stays the same, decreasing over time (variations in the middle can be used, reflecting the strength of a particular trend: 


\section{Step 4: Scoring}

(via stones in a pile, white / black board, paper, poster etc.) \& trends (5 or 10 years?)

a. Individual scoring

b. Group scoring (added up from individuals or doing a new group vote, but then discussed in plenary or small groups, see also step 5)

\begin{tabular}{|c|c|c|c|c|c|c|c|c|c|c|}
\hline \multirow{2}{*}{$\begin{array}{l}\text { Indicator } \\
\text { Question } \\
\text { number }\end{array}$} & \multicolumn{2}{|l|}{ Name } & \multicolumn{2}{|l|}{ Name } & \multicolumn{2}{|l|}{ Name } & \multicolumn{2}{|l|}{ Name } & \multicolumn{2}{|c|}{ Group Consensus } \\
\hline & Score & Trend & Score & Trend & Score & Trend & Score & Trend & Score & Trend \\
\hline \multicolumn{11}{|l|}{1} \\
\hline \multicolumn{11}{|l|}{2} \\
\hline \multicolumn{11}{|l|}{3} \\
\hline \multicolumn{11}{|l|}{4} \\
\hline \multicolumn{11}{|l|}{5} \\
\hline \multicolumn{11}{|l|}{6} \\
\hline \multicolumn{11}{|l|}{7} \\
\hline \multicolumn{11}{|l|}{8} \\
\hline \multicolumn{11}{|l|}{9} \\
\hline \multicolumn{11}{|l|}{10} \\
\hline \multicolumn{11}{|l|}{11} \\
\hline \multicolumn{11}{|l|}{12} \\
\hline \multicolumn{11}{|l|}{13} \\
\hline \multicolumn{11}{|l|}{14} \\
\hline \multicolumn{11}{|l|}{15} \\
\hline \multicolumn{11}{|l|}{16} \\
\hline \multicolumn{11}{|l|}{17} \\
\hline \multicolumn{11}{|l|}{18} \\
\hline 19 & & & & & & & & & & \\
\hline
\end{tabular}

Box: Matrix to Capture Results - Communities' scores and trends

\section{Step 5: Group Discussion}

- Going through the final score sheet and discuss reasons, weaknesses and strength of their landscape etc. 


\section{FoSRA Tool f: Sense-making - Key Informant Interviews}

Mapping perceptions on change and its implications for FNS programming through Stories of Change (key-informant interview) with the following participants (1.5 hour in total):

$>$ local community leadership (focus interview on community-level perspective of the key-informant)

$>$ community elders or spiritual leaders (focus interview on community-level perspective of the key informant)

$>$ representatives of relevant ministries including agriculture/forestry/livestock/water at locality level (focus interview on the sectoral perspective of the key-informant)

$>$ relevant private sector companies (focus interview on private-sector perspective of the keyinformant)

$>$ NGOs/international organisations (focus interview on humanitarian-development-peace perspective of the key-informant)

\section{Shocks \& Stressors:}

1. What have been main changes in the nature and number of shocks and stressors over the last 10 years?

2. What have been the main changes in terms of impacts of shocks and stressors on the lives and livelihoods of people over the last 10 years?

3. What do you think should or can be do about this?

\section{Risk Management Strategies:}

1. What have been the main changes in preparing for the impacts by shocks and stressors over the last 10 years?;

2. What have been the main changes in reducing the impacts (mitigation) of shocks and stressors over the last 10 years?

3. What have been the main changes in coping with the impacts of shocks and stressors over the last 10 years?

4. What have been the main changes in terms of recovering from the impacts of shocks and stressors over the last 10 years?

\section{Resilience Capacities:}

1. What have been the main changes in the capacity to withstand (absorptive) the impact of shocks and stressors over the last 10 years?

2. What have been the main changes in the capacity to adapt (adaptive) to alternative livelihood options in the face of shocks and stressors over the last 10 years?

3. What have been the main changes in the capacity to transform (transformative) to new livelihood strategies in the face of shocks and stresses over the last 10 years?

\section{Fodder Programming:}

The questions below are to be contextualized in line with four different future scenarios for pastoralism, being: (1) good market access and good rangeland access, (2) good market access but bad rangeland access, (3) good rangeland access but bad market access and (4) bad rangeland access and bad market access. Before answering the questions below, determine in which scenario(s) your community or beneficiary group finds itself (can be one or multiple).

1. What beneficiary/community needs should be considered in design \& implementation of fodder Programming?

2. what beneficiary/community preferences should be considered in design \& implementation of fodder Programming?

3. what beneficiary/community existing capacities should be considered in design \& implementation of fodder Programming? 
Wageningen Centre for Development Innovation

Wageningen University \& Research P.O. Box 88

$6700 \mathrm{AB}$ Wageningen

The Netherlands

$\mathrm{T}+31(0) 317486800$

www.wur.eu/cdi

Report WCDI-21-154
The mission of Wageningen University \& Research is "To explore the potential of nature to improve the quality of life". Under the banner Wageningen University \& Research, Wageningen University and the specialised research institutes of the Wageningen Research Foundation have joined forces in contributing to finding solutions to important questions in the domain of healthy food and living environment. With its roughly 30 branches, 6,800 employees (6,000 fte) and 12,900 students, Wageningen University \& Research is one of the leading organisations in its domain. The unique Wageningen approach lies in its integrated approach to issues and the collaboration between different disciplines. 



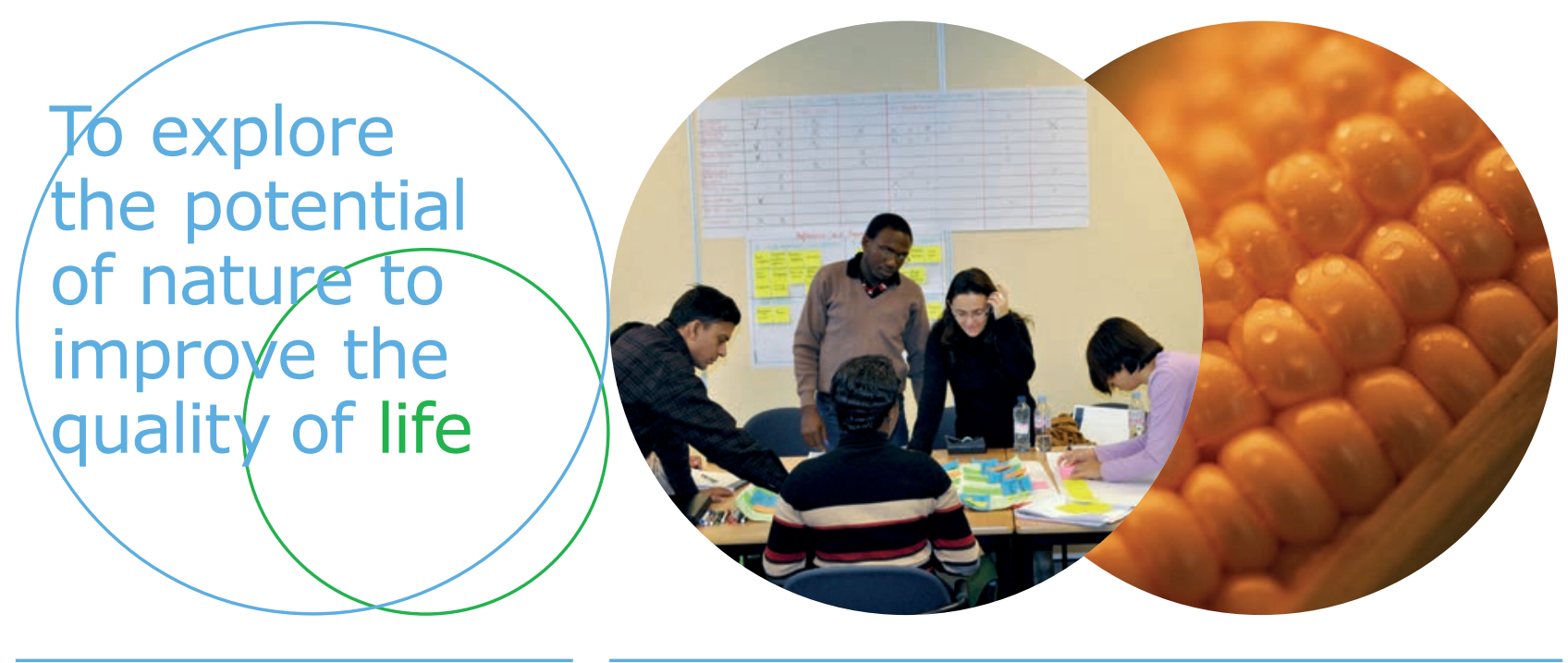

Wageningen Centre for Development Innovation Wageningen University \& Research P.O. Box 88 $6700 \mathrm{AB}$ Wageningen The Netherlands $\mathrm{T}+31$ (o)317 4868 oo www.wur.eu/cdi

Report WCDI-21-154
Wageningen Centre for Development Innovation supports value creation by strengthening capacities for sustainable development. As the international expertise and capacity building institute of Wageningen University \& Research we bring knowledge into action, with the aim to explore the potential of nature to improve the quality of life. With approximately 30 locations, 6,800 members (6,000 fte) of staff and 12,900 students, Wageningen University \& Research is a world leader in its domain. An integral way of working, and cooperation between the exact sciences and the technological and social disciplines are key to its approach. 